\title{
Farm Behaviour and Incentives for Animal Welfare: On Stimulating Interest in Cow Life Expectancy by Industry Attentiveness
}

\author{
E. A. Nuppenau ${ }^{1}$ \\ ${ }^{1}$ Department of Agricultural Economics, Justus-Liebig-University Giessen, Germany \\ Correspondence: Ernst-August Nuppenau, Institut fuer Agrarpolitik, JLU Giessen, Senckenbergstrasse 3, \\ D-35394 Giessen, Germany, Tel: 49-641-993-7022. E-mail: ernst-august.nuppenau @ agrar.uni-giessen.de
}

\author{
Received: April 19, $2018 \quad$ Accepted: May 4, $2018 \quad$ Online Published: May 23, 2018 \\ doi:10.5539/jfr.v7n4p55 \\ URL: https://doi.org/10.5539/jfr.v7n4p55
}

\begin{abstract}
This contribution deals primarily with a new concept derived from institutional economics, to improve animal health (eventually welfare, depending on the use of synonyms and actually measured as cow life expectancy, i.e. in figures: number of lactations). Based on consumer willingness to pay, it investigates a potential collaboration between a dairy industry whose aim is to diversify products and some farmers whose intention is to request compensation for a change of practices. For finding practical attributes for health, we have a focus on practices promoting numbers of lactations, currently at a low level in conventional farming. We distinguish farm types by strategies asking why most farms are primarily aiming at maximal efficiency (feeding concentrates for high milk yields and having no grazing). Vice versa: this has raised public concern because (with big herds, high milk yields and minimal lactations) farmers seem to stress animal welfare. We assume WTP exists for an improvement in animal health (though diffuse so far). I.e. on the one hand as a symptom of crisis, successes for gestation are low (almost half compared to those of farms "caring" for animals). On the other hand better practice can be financed if targeted by WTP.

Further assumptions are: even the industry may admit problems with animal health, and within consumers' and citizens' circles, there is an increasing awareness and that WTP (finance) may enable private solutions. WTP could be used for those farmers doing better on animal welfare; but so far, markets have failed. We are confronted with different strategic behaviour of farmers (by sectors) whose commencing points (as observation and deliberation) must be a willingness to change practices. A starting point should be insight into behaviour(al) change and willingness to increase animal health (gestation), yet based on compensation. Compensation can be used to get more farmers interested in animal health, but it must be differentiated according to actions for improvement. In an institutional economics analysis of animal welfare, we will work out a concept of optimal compensation, preferably achieving cooperation between a dairy industry and willing farmers to lodge payments received from consumers. It means working on participation of actors in product diversification (milk identified by different sources) and transfer of money to those farmers who are actually working for animal health concerns. The paper further addresses selection of farms which manage to achieve set health goals and assure confirmation of achievements in increasing health. The goal is to increase the number of lactations. By utilizing contracted numbers of lactations as the basis for modelling a quantitative criterion which adequately shall reflect aspects of working for animal health (such as feeding practices, grazing, better husbandry (space and straw), caring (stress recovery), etc., is worked out and animal welfare shall improve.
\end{abstract}

Keywords: economics of animal welfare, institutions, bargaining model

\section{Introduction}

There is an ongoing, generally normative, but eventually also specific moral debate on animal welfare. Further it is a specific debate on consumers' and citizens' preferences, in order to create willingness to pay WTP for animal welfare (for instance in Germany see BMEL, 2014), which can be used as compensation for farmers willing to change practice. Particularly we find discussions about farm practices and, in the dairy industry, of financial needs in supporting detailed programs about farming practices improving life expectancy of cows. In contrast, there is a lack of concepts on how to achieve more animal welfare through channelling WTP to farmers. Concerns are raised about health and kindness towards animals and whether, for instance, especially cows are solely means of milk production vs. fitness and health for reproduction. Likewise, practices are prescribed which 
aim at animal friendliness (Mench, 2017); but not much is done by institutions to achieve it. There is a further debate on underlying reasons why we have the issue. And there is a broad discourse which conveys many aspects such as: (i) deliberations on mislead farm structures (industrial production at large farms), (ii) emerging public concerns on husbandry (rearing of cows in farm sheds at minimized space vs. (iii) grazing and needs for natural behaviour, etc.; Thompson, 2004). This may be philosophical and technical, but it also deals with (iv) preferences, (v) public interference vs. private rights (on good practice, seemingly "scientifically" approved practices, rights), (vi) mechanisms to achieve more animal welfare and (vii) coordination (by market vs. governance), which regularly call for policy. However, most frequently the concrete debate concerns rules (on the side of proponents for interference), costs (on the side of the industry) and finding generic instruments (on the side of society) (Ohl and van der Staay, 2012).

In this contribution we add an institutional economics aspect to the discussion, showing that improved coordination may help (i) to make consumers more comfortable, (ii) farmers to gain through changing their practice and (iii) to mitigate the conflict. Looking at institutional economics, incentive structures and initialising transactions between consumer/citizen and farmer/industry etc., these are imminent challenges for transactions. Indeed, as public discussions can be emotional and are often far from being associated with reality, a concept is needed to work in reality. We will economize (monetarize) the issue and display interests. It is crucial to find out what can be asked of farmers that are struggling for survival in a competitive market, and what a realistic compensation could be? Yet, farmers have to be addressed differently.

To further pinpoint the problem, so far society mainly seeks for solutions which are expressed as regulations on practices (husbandry of animals, genetics for cows at lower yields, feeding adjustments, etc.) as well as seems to vote for inspection of farming, i.e. direct government interferences and control, etc. (Mench, 2008). But can we really consider regulations to be the most effective solution? Regulations are mostly considered interventions and create passive behaviour. They are proposed as laws, ordinance, interdictions and guidelines, etc. and thereby an authority (hated by farmers) infers in business and is needed. Though some interventions shall even work as active prescriptions on ways of treating animals (for instance wished by animal rights activists), they increase costs and destroy comparative advantages. Indirect instruments such as incentive schemes are rarely discussed. Interventions are not incentive oriented; rather, they express a mood of strangulating business (in the opinion of farmers). As a consequence, direct interventions are strongly objected and politically undermined through lobbying and exercising power (in legislation). This has resulted in a political standoff. In many countries as well as in case of the EU, interventions lack institutional design. In this paper, in a first step, a conceptual framework is developed which outlines a straighter economic logic, running from incentives to behavioural responses of farmers. It is considered a way to find a compromise on the basis of a win-win situation sponsored by WTP, which shall lift stand-offs using different strategies of different farmers as a source of volunteering. In a second step a government can be introduced, since we may believe that voluntary actions are not enough. Then a government, being interested in animal welfare on behalf of its citizens' preference, shall seek further ways to raise money, eventually within a process of farm structure change, which has been negative for animal welfare so far.

If a more conciliatory intervention is envisaged, by apparently seeking approval through less resistance because a win-win situation is anticipated, the argument for incentives being better than regulations must be elaborated further on the basis of what is transacted for what? We need to model the envisaged causations that economic instruments can have similar effects on animal health, although at different costs and level of acceptance than intervention. In this contribution a suggestion is made to explore consumers' WTP, which is attained by the dairy industry to channel money to a definite segment of farms that are willing to improve animal health.

However, it is not the intention of this article to contribute to an "ultimate" solution, such as the "market will do it" vs. "intervention"; rather the objective is to explore the animal health (wealth) issue specifically from the narrower point of view of marginal improvements by increasing lactation numbers. Lactation is embedded in animal welfare: It shall be an interest-driven approach. This means we have to make animal health concrete for negotiation, even if there is the danger that someone will say it is too simple. We need contracting parameters and take life expectancy (lactations) and natural forage (grazing area) as ones to negotiate. Then economics can be streamlined with animal husbandry and health for WTP and compensation. A focal point, from an animal science point of view, is that cows nowadays are more productive, but calving and the number of lactations have declined (Rodriguez-Martinez, 2008), and this can be changed by breeding, veterinary attention and grazing. There are many reasons put forward: incl. (i) "better" genetics for higher milk yields (cows nowadays are so much "better" but unhealthy at all), (ii) veterinary aspects (that "artificial" insemination has high costs), (iii) foraging (energy is the most important ingredient in the production of milk beside protein, no more roughage), 
(iv) even generic economics (it does not pay to have more lactations, and remounting is cheap), etc. But reality tells the reverse. For those who try to understand animal health it is important to elaborate on behaviour that links number of lactation to strategies, i.e. it is important to go beyond "normal" science scopes. It has to be asked: what is the agronomic background for behaviour (towards incentives and participation in schemes)? How can strategic background and farm practices change the application mode of incentives? Again, the aim is to elaborate on cost effective policy instruments besides regulation. A guess is that diverse strategies exist in the industry and that it particularly makes sense to address more willing farmers and to obtain a shift in strategic behaviour by some farms (not all). Well, in a more detailed contemplation on the system, an even more complex problem would emerge.

\section{Study Background}

Here (to acknowledge the background) we firstly investigate what could be meant by animal health and welfare (apparently for institutional economics). Note, the specification is intended to obtain an exchange and incentive scheme, not a moral statement. In fact, the underlying issue would be related to genetics, disease, husbandry and foraging system, as these have shaped the modern farming system. These seem to have problems with animal welfare (Dobson et al., 2007). We merely seek a trigger for linking improvement with payments on basis of improving life expectancy and compensating farmers working for it. Again, it is not the idea to discuss animal health in the sense of curing or preventing "diseases" by paying for veterinary services, etc.; rather we want to address practices, efforts and behavioural change to create an environment (will) for increasing lactation numbers. There might be many reasons which have been put forward to explain transition from the past (with cows living longer in traditional systems) to the most prevalent, new type of animal husbandry (short lived cows). In fact, today's present high yielding cows perform badly in reproduction. But is this unavoidable? We take an economic (though different) position (BMEL, 2015) and anticipate needs for change, focus on society's concerns (incl. WTP) and do not take current circumstances as given; for instance that farmers prefer high yielding cows. The aim is to contribute to conflict mitigation stating there is a problem known in society (BMEL, 2015) and that money can solve it.

To be clear, the author is not of the simplistic opinion that by definition (i.e. those cows which produce much milk are having health stress) cows are routinely considered unhealthy; i.e. if milk yields are high, all cows are automatically ill; rather practice in detail matters. Any farm(er) has the right to claim he is doing the "best" for cows; but citizens may see it differently. To sketch the issue: today, many cows (admittedly, mostly in highly efficient dairy farms) which deliver more than 11,0001 of milk per annum have problems with gestation (they have less lactations than traditionally). Yet, at the expense of caring for longevity, today's cows are used regularly for only less than 2 to 3.5 lactations (on average) and veterinary costs are high. Being used short-term, which is an indicator that metabolism and physiology are in stressful condition (Ingvartsen et al., 2003), cows have seemingly become an input object (like cheap tractors) which do not deserve repair. (Yet, this is not a moral statement, but it refers to overuse; note that there might be a problem with rationality of farmers, which however goes beyond the scope of this contribution). We think it is not even "economically rational" from society's point of view. We are not so much concerned with complaining about this, but rather seek a solution which is embedded in farm structure and institutions, like contracting for health coming from money. Also, we will not inquire to unknown "reasons" why some, though not all farmers, behave towards animals as if they were "objects" that can just be disposed of. Rather we will suggest a type of approach which captures specifics of milk industries (branding) striving for animal friendliness, for example, of citizens to be "responsible". Below, we will further see a driving force (in terms of strategic choice for high yielding) which is re-enforced by land prices (O'Kelly and Bryan, 1996 as well as Vranken and Swinnen, 2006). From an economic point of view, strategies differ between farms and are stated over factor endowments, market access, location, etc. There may be multiple strategies; but for modelling, it is a must to synthetize strategies (reduce them to cases, here 2) and see how institutional amendments can work.

Our approach starts with three observations as well as with potential mediation options: (1) Cows which are fed with less concentrates (soya for example) give less milk but live longer; this has been revealed by many studies (Walsh et al., 2011, Rauw et al., 1998, Pryce et al. 2004). However, high yields based on soya vs. grazing is considered a trade-off or, differently expressed: higher milk yields (less grazing but forage from concentrates) create negative externalities of reduced lactation periods and health problems; i.e. if it is expressed in lactations, good grazing (outdoor) increases the numbers of lactations. Let us further assume that the general public is concerned about this and individuals have a willingness to pay for milk from cows which live longer and graze. In that case, how could money be channelled grazing? WTP has to be called in action and money (willingness to accept: WTA for preferred practices by willing farmers) has to be made available; for instance, WTA shall 
change practices such as feeding (grazing vs. concentrates). Yet, may any other practice be involved?

Where to start in terms of selecting willing farmers? Perhaps there is already a stratification of farms towards WTA, based on yields (genetics), practices (feeding) and strategies (cost minimization) as well as on the fact that only few farms are purposely working for high yields, ending in short-lived cows. Others still use grazing animals at lower yields, but currently see no opportunity to survive. Independently, real commercial farms continuously pursue a strategy of attaining the highest yields (which, for them means minimizing unit costs per litre of milk) and others are less commercial. We can stratify farms. To start here: "efficient" farms usually have large herds, use the latest technology, primarily work with bought concentrates, and cows are a means of production, etc. (see technical efficiency and productivity of dairy farms in three EU countries and the role of CAP subsidies, etc.: Zhu et al., 2012). So to speak, they farm "at best" in the industrial manner (Fitzgerald, 2003). In case of intensity, these farms, for example, have almost no outside dwelling of cows; their roughage is maize, they are fully mechanized (incl. robotics for milking, computers, etc., Winston et al., 2010).

On the other side of the spectrum there are (still, though declining) farms operating in a more traditional way of practice, preferring grazing as source of forage, different types of cows, etc. Apparently their strategy is different. They have lower yields; cows are sustained by own labour (intensive foraging production in winter: hay) and even have outside grazing on meadows; perhaps maize use is limited, hand labour is pertinent, etc. Therefore these farmers pursue strategy by making only minor investments in technology. Farms typically work with less financial capital; they are smaller and it appears as though they think more about animals (in terms of funds vs. inputs: Alvarez et al., 2008) and life-expectancy matters.

As hypothesis in identifying a strategy: not all farms do the same (strategically), in order to maximize "surpluses" or "value added". By surplus for instance, we do not mean the usual simplified objective function of "cash maximization"; rather we use the term strategy and surplus as a proxy for internal investment in livestock, capital or land, etc. We see both, long-term maximization of capital or funds and short term cash maximization. Cash maximization might be misleading in an environment of high dynamics, structural change, and capital formation as in farming. We presume farms want to survive and create strategies for long-term stakes (Weiss, 1997). In contrast to a simple economic theory of short-term maximization, which underlies an economic thinking of all farmers being equal (Ford and Shonkwiler, 1994), farmers can (should) be differentiated by their economic situation (institutions regulate objective "functions": March, 1994) and strategic behaviour matters. It is our underlying hypothesis that in the end, farms follow different maximization strategies (frames) depending on the situation, which in turn has an impact on animal health. (Maybe animal welfare is not an overall concern, but animal health and lactations are concerns for some farmers below.)

A further assumption is that there are "entrepreneurial farmers" who block, but are concerned about images of industry. They seek gaining a maximum of rent from land (land value as capital available from own land) and regard cows as means of production; mostly, these farms are expanding, large farms; they use latest technologies which support them in working at low margins and they are very competitive (customarily they are called estates, even corporations, etc.). Today, they are capital intensive units and labour and cows are regarded as machines. Units are driven by recovering investments and aiming at capital revolving. Perhaps based on huge credit lines, investments by banks, holdings and financiers, etc., they are interested in maximizing returns on investment and occupy dairy processing capacities because of low price requests; all being good for export. Still, objectives have to be complemented with assuring value added (cash flow) to meet payments. Such farms, drawing upon latest technologies, use high yielding cows, which are short lived and maximize land values.

In contrast, as a diversified strategy (straight, not because of moral sentiments, which are not the topic here, but as a survival in farming), smallholder farms might prefer to maximize the "value" of their animals. It is the underlying paradigm that differed long-term strategies exist, which farmers can aim at. What is meant by value and what does it mean? Apparently, for economists, perhaps only monetary values exist; but this definition might be too narrow. In theoretical deliberations about economics, it might become evident that a farmer pursues economic values for survival in structural change (Zimmermann et al., 2006); he is presumably a simple minded economic person (homo economicus); but reality is more complex. One can doubt pure, short-term economic rationality (yet in its narrow sense) works for all, it is very orthodox (if applied by all farmers). Perhaps it is: "you will see what you want". In contrast, by heterogeneity vs. homogeneity in objective functions, for example, strategy has been explored for agent based modelling fruitfully (Robinson et al., 2008); you gain if you are better than orthodoxy! Besides ideological questions, here the idea is that some farmers still consider themselves as working with animals and that working well with animal conforms to "norms" (Elzen, 2011).

In the case of these farmers (for the moment called "non-commercial"; note that not all farmers work 
commercially as described above), animal values (as norm, synonym for stocking capital) shall count more than the maximization of profits. Although income is still needed, it might not be the priority; yet it is a matter of priority-setting in the context of multiple goals and eventually traditions whether farmers are singled mined. As observation referring to situations of having different strategic goals (high milk yields vs. low replacement, use of roughage, etc.) some farms incidentally can and have cows with more lactations (lower replacement rates: Müller-Lindenlauf et al., 2010; not necessarily only in organic farming). We see "lactation periods" striving to be a norm (of health), which is important for some farms. Instead of capital as land value maximization, of which they still might be short, some (farmers) regard animal values as being important because they are another mode of "capital". However, it is not an absolute norm and strategies can shift because opportunities vary. At the same time, because long-term goals may matter, permanent income (primarily income comparable to off-farm income) is envisaged; this is even important for daily (annual) operation.

Let us go further in making strategies distinct. Let us argue about objectives: one could believe that some farmers maximize herd size. But what is the value of herd size, if cows are "not of good quality"? Yet, a larger herd size requests more land if quality is low. There is the logic to expand into quality of animals. We can confront strategies with land capital vs. animal capital. A venue which has scope (and was even present in traditional society: Firth and Yamey, 2004) is that a farm could acquire more capital through longevity of animals (rather than land expansion). It brings us to the question what capital is for "real" farmers. In the extreme way we may envision some farmers give priority to care for animal health (wealth) if it is their "natural" (only) capital. So we have to argue: does this "natural capital" make economic sense? (These farms count lactations multiplied by the number of cows). This implies that a farmer would decide on number of lactations (Wagner, 2016). Our argument is a bit different: (i) issues of cost counting in remounting emerge (costs are different for each individual farm) because cow purchases are deficient. Then, if one calculates foraging of heifers correctly, cow values are different in terms of life expectancy. I.e. (ii) the advantage of having more lactation can best be understood by bearing in mind three dimensions: (iia) cow age, total milk produced per cow during its lifetime (for example 3 x $11000=33000$ litres vs. 7 x 7000=49000 litres) and depression. Considering (iib) and avoiding depression of milk production in future lactation is important and (iic) to sum up, there is scope for more milk increasing life expectancy.

It has to be asked in detail what the reason for a strategy of animal health is and how farming reacts in practice. In case of caring for potential depression of yield (a term introduced for the calculation of future yields to check the economics of continuing with a cow: Wagner, 2016), depression can be minimized by (iii) caring for health, but this depends on labouring (for instance grazing vs. machine feeding). It is postulated that animal health and welfare, as a strategy, can be expressed through working for health In case of animal friendly farming it becomes different. There is a WTA costs but also to get them compensated usually expressed in a "good price" request (see below). For compensation we need to recognize opportunity costs. In large farms with hired labour it will not work out because these farms rely on hired labour. In fact, a farmer can be "paid" for animal health, but this primarily works by using family labour (i.e. if milk yields are low and lactations are the focus). Anyhow, the choice of strategy depends on off-farm costs for labour. Labour can be invested into obtaining longevity of cows, but not always. Some farms may wait for incentives. Still we assume that some farmers are more "traditional" (in the sense that they pursue a strategy of good animal rearing with healthy animals which can show superiority). Then it is a positive investment. In contrast, we see modernizing attitudes and they work for outlooks which see animals as inputs, only (Franklin, 1999). In fact, labour costs are a crucial aspect. Maximizing the long-term value of animals needs more labour and it is only "economic" if there is a "surplus"; vice versa, labour gives "capitalized-ability". Animal welfare relies on a subsector where cheap labour is used. In contrast big herds (in a modern sense) require "big" investments, which are not affordable for many farms; they quit or look at animal capital to make them distinct. Then animal welfare and capitalizing for longevity of cows need support.

Furthermore, perhaps a small landowner can rarely become a large commercial farm. He has no chance to capitalize on land. If there is competition with regards to land, small farms will give up or capitalize on animals as a last chance. Land acquired by large farms is then mostly used for production of maize, which in turn is used as supplementary feeding for ruminants, at minimum, and concentrates (soybeans) in achieving high yields are the option to leverage land capital. A chance for small farms to survive is to pursue the animal value strategy, i.e. investing in labourism with genetics that contribute to long life, i.e. if there is an incentive. Again, it also means to look at the best use of grass and to offer grazing to cows which have special genetics for lower yields if supported. I.e. having a grazing cow is an asset if grazing is supported. At the micro level, if milk yield stabilization (and compensation) works out at a low level, based on grazing, there is a new scope to follow a strategy which considers cows' life expectancy to be an asset; but subsidizing grazing is not an asset per se; it is 
a means for health. It should be limited to low yielding farms. Our enquiry articulates a promotion of strategy (different from commercial) resulting in different behaviour. The success depends on the farm structure. At a macro level, for example a landscape, region or province, it can be important to know how many large and small farms co-exist. Co-existence is a way of bringing about the outcome of private good (milk) and social good (societal acceptance of farming).

\section{Coexistence, Distinction in Strategies and Grounding of Behaviour}

The coexistence of more or less animal welfare oriented farms in a farming community (system) has several implications; at least it shall help us in finding a compromise and institutionalization of incentives. As high yielding farms, which feed animals primarily with concentrates at "maximal rates" and which strive to get the "most" out of the cows in the short term, are usually more competitive at the land market, repercussion from other markets (land) are to be included. It could be assumed that low yielding farms are about to vanish because they can pay less for land. But we already spoke about compensation, so some are still there and compensation increases competitiveness. Actually we can observe the interaction of land and output prices on farm optimization (Roel and Ge, 2005). Strategy in favouring large farms may currently win and we only see niches for less intensive farms that prefer grazing. Grazing is losing ground in structural change. Land prices increase permanently (and from the aspect of health of animals, the situation deteriorates because grazing does not pay). Especially where there is rapid structural change and land gets scarcer because more farms want to convert their business, land scarcity (prices) is an indicator of outcompeting small farms (Zimmerman and Heckelei, 2012). On the other hand, control of land markets and subsidization of farms with grazing might be a tool to control the performance (of the whole sector striving for animal welfare). Furthermore, it has to be acknowledged that the overall agricultural sector is still subsidized (though, at the moment, by land oriented subsidy) keeping farms alive. Yet, new payments according to grazing should promote co-existence.

Secondly, concerning co-existence and filling niches as well as improving the overall image of dairy industries, we must come to a description of strategies. We want to make farms distinct (perhaps ideally but also for modelling) to address them correctly. A core hypothesis is that Land Value oriented Farmers (LVF, which use latest technologies, high yielding cows, etc. and inputs like protein concentrates such as soybeans, minimal roughage, etc.) seek to get a leverage for land in maximizing capital returns. Since land is scarce and has a high price (at least in areas of intensive milk production) and because many farms want to capitalize on this (i.e. in respect of different opportunities for them to get rich) they follow leveraging as goal. We work with this goal (below) and try to find out how it fits into a picture of actual behaviour (also below). The idea is to link a special economic behaviour, initiated by strategical pursuit; to animal health measured as lactation (here low life expectancy). The analysis shall help us to put the issue in a bargaining model for (dis)-improvement of health (low gestation rates of cows) which is adopted by farms jointly with the other strategy (to be outlined next). Cooperation and bargaining together shall be beneficial for both sides: farms that pursue healthy cows and farms that want to be efficient.For this we will include consumer WTP, but targeted at farms which confine themselves to working for animal health. With a WTP for animal health (wealth), used to increase cow life spans, the strategy of being willing to accept (WTA) by farmers can be further elaborated.

To summarize briefly, our proto-type in behavioural modelling will serve to identify interactions between cow life (as choice), choice of technology and bargaining in segmented markets. The idea is to promote coexistence. Thirdly, the role of the public can be elicited showing how public concerns and support can be deployed to get a welfare improving (win-win) situation. It is the aim of the paper to show improvements are possible, but from a political-economic point of view The topic is measured as change (in life span of cows), presuming that participants in a bargain have power to lobby and that government facilitates injection of WTP for animal welfare in a system of coexistence. Those who dream of a perfect world in which all farmers convert to "a world of healthy cows" will be disappointed (because the suggested approach is selective). But it engages actors in reality of strategic behaviour and power, while seeking to get marginal improvements.

Fourthly, the approach commences by constructing an argument for an alternative strategy. The strategy is built along a long-term perspective in farming. Referring to multiple objectives and seeking labour returns at the forefront, a farm could quit structural change (Weiss, 1997) or pursue different options; i.e. if it wants to stay in business it has to find a niche with compensation for animal welfare practices. The assessment of distinct situations with special livestock and incentives for "good" practices is the key and farmers should be successful with regards to survival. For instance, and since it is the focus, how can an animal value (welfare) oriented farm (AVF) built a strategy be justified and how can it compete with lower yield against LVF? Note that, in the beginning, the strategy shall apply to niche farming and has to be seen in conjunction with a struggle for survival. Hitherto, the background is: a dynamic sector in which farmers utilize individual strategies to try to get most in 
case of threat by structural change. Structural change can be mostly observed at the level of ceasing production or investing in highly capital intensive farming equipment. In contrast, some farms still pursue animal welfare (AVF). As it will be communicated with consumers below a technical level, animal welfare becomes identified with "(i) high number of lactation and (11) grazing", i.e. it is a strategy which shall be verified (in comparison to a strategy of "few lactations and leveraging of land by resource purchase" (LVF). Here, caring for animal means farms purchase less concentrates and leverage scarce resources less. A crucial aspect is to find a measure for assessment and factors which determine success of strategies (Dauderstädt, 2013). We adopt the perspective that farmers have to have a long-term perspective on what to maximize to improve their situation. So it is not on technology only. We assume that there is a race for land and growth in capacity which is reckoned to be the basis for survival of LVF; so farm size matters and will be discussed. Dairy farmers seek to intensify and use capital to get economies of scale, however this makes the relation to animals more technical. AVF should be different.

Fifthly, a comparison of long-run success is difficult because in the case of standard leveraging of capital and land, this strategy does easily result in system limitations. Driven by innovation, treat-mill and scope of survival by a few (best) farmers (Sunding and Zilberman, 2011) who survives? For the design of incentives for animal health note that small farms will quit the race because of support. The land market and its dynamics have come into play and there is feedback which is routed in the "productivist" view (Dyball and Newell, 2015) of food system dynamics. In contrast, sixthly and potentially, following AVF strategy, this strategy is not at all popular as a strategy per se because of labour requests. Rather farmers which are under pressure in the race for survival may only trust in expanding business if there are signals (payments) of support from dairy industry. Deliberations and negotiations are needed to find participating farmers in working out individual commitments. The underlying hypothesis is that some farmers (AVF) may pursue a strategy of creating capital associated with an increasing number of lactations per cow. The strategy has to be competitive at the (land) market and it has to meet income needs of AVFs. Similarly, we have to elaborate on triggers which can encourage those farmers who have not yet indicated that they will potentially pursue the AVF strategy. Then prices matter. From the point of feasibility, it has to be checked what can be regarded as a "fair" price for milk, which supports competitiveness and is there scope for direct payments for the services provided.

Finally, as a question for coexistence, it could be questioned whether the AVF strategy works empirically and is reliable. At least there is still diversity in dairy farming systems in many places in Europe (for example Choisis et al., 2010) and dedicated farmers show it works with AFV; though it needs attraction. The qualitative argument for coexistence is that both types of farmers will see a need to capitalize resources, yet in different ways. More frequently, lactating cows are an asset for farmers with limited access to capital because they are also collaterals. AVF will not work with hired labour, but will rather, and to a certain extent, be self-exploitative (yet with minimal income request). High yielding cows on the other hand, which have to be replaced after a short while, cannot be an aim of AVF because AVF need reliable production from restricted own resources, such as limited grazing areas. Also, they usually work with cheap equipment, don't have enough collateral and are under the risk of failing with high capital intensive husbandry types. In terms of conventional efficiency, they are inefficient (Zhu et al. 2012). But incentives will direct farms towards recovering growth options from "good" cows.

\section{Modelling of Objectives, Constraints and Behaviour}

A prime step for achieving negotiations as well as for getting parameters to be negotiated (in contract design in order to jointly settle interests and finding measurement of power: Zusman, 1976) is to calibrate behavioural models for participants. These models shall include animal welfare as an indirect variable. We foresee (as is argued above) life expectancy as representing animal health and welfare. (That may not be a satisfying view of science, since it is normative; Kielland et al., 2010; but we nonetheless assume this). Note that we aim at a formal representation for modelling. We state the interface that lactation can become negotiable as being a source of concern, and create WTP in terms of being acknowledged by consumers/citizens. This needs market segmentation (Figure 1, below) and LVFs shall benefit directly. Indirectly, LVFs shall benefit because dairy products get a better image. Compensation shall be paid to those farmers who do a "better" job, i.e. care about animal welfare. This cooperation takes place at sector level. The intention is not only to derive a behavioural platform which shows drivers in terms of specialization and leveraging making years of lactation; rather it is the intention to see the scope for contingent behaviour. As another aspect (since, in academics, it is an exercise of modelling) variables are defined as continuous, not discrete; this concerns primarily lactation numbers and hectares per cow for grazing (below). Also, we will work with average numbers per herd not individual cows. This might be coarse, in particular with regard to the depiction of real farm operation and the description of management, however it is part of modelling and we can only stylize facts. It means we cannot care for any specificity. 


\subsection{Commercial (Land Value) Farms}

As an apology, it might be wrong to call a farm which has cows with "few lactations and purposely leveraging of land" a "bad" LVF, i.e. being a commercial farm, because it can be claimed anybody is commercial; but it simplifies language. Firstly, it is assumed for a commercial farm, being efficient and using the latest technology that it wants to most perfectly leverage scarce capital. The capital value increases (given the background of prolongation and of proper management) on the basis of existing ownership of land, and it is based on the value of farm (land) which is triggered by the intensity of farming (number of cows per ha). In that regard "max. yield" is a goal which constrains (pushes) farm operation towards the best financial balances, and an annual target is given for milk volumes. (The target is a matter of individual choice). It says that capital involved in milk production has to be replicated and returns (gains on asset, land) are needed. In other words (or mathematical terms), the long-term value of land (land rent) is a secondary goal and the modeller has to recognize that capital flows are involved. In turn, if money is borrowed, this money (given as credit) must "return" (revenue) from operating the herd. Milking cows must meet capital flows and more. At the core is "value creation for own land (land rent)" plus value added which is created for hired land; it is a "must" (constraint) as situation. We can include purchasing power to acquire land for such farming and a surplus from operation. In principle, the constraint is about capital creation and it is assumed that a decision making land owner has a target $\mathrm{v}$. The target, though it is subjective, enters the bargaining later on as an element of alternative for investment alternative.

We assume that a target (a land value) shall be reached in a period of " $t$ " years, where $c$ is a cash flow which adds to the long-term values, but it can also be eaten up by the flow analysis.

$$
V=\sum[1-\boldsymbol{v}]^{t}\left[\boldsymbol{r}_{i o} \cdot \boldsymbol{a}_{i}+\left[\boldsymbol{r}_{0}-p_{1}\right] \cdot a_{r i}+c_{0 i}\right]
$$

As per annum, in a static analysis, we drop the summation and presume that any year is equal. Otherwise one can work with an infinite series. The cash flow is stated along area "a" and return on investment $r$ and price of land $p$ for rented-in land being deducted; while $v$ is interest.

Then objective (2) prevails on basis of herd size (cows) $\mathrm{k}$ and yield y (lactations $1_{\mathrm{o}}$ are fixed at a minimum and not relevant); cows are bought for revenue and soya s and work w for costs $\mathrm{c}$.

$$
\max \pi_{c}=[1+\boldsymbol{\rho}]\left[\boldsymbol{p}_{s}^{k}-\boldsymbol{p}_{p}^{k}\right] \boldsymbol{k}_{o} \boldsymbol{l}_{o}+\left[\left[\boldsymbol{p}_{l}^{m}-\boldsymbol{c}_{o}\right] \cdot \boldsymbol{y}_{o} \cdot \boldsymbol{k}_{o}-\boldsymbol{c}_{s} \cdot \boldsymbol{s}_{o} \boldsymbol{k}_{o}-\boldsymbol{r}_{s} \cdot \boldsymbol{w}_{s}-\boldsymbol{c}_{o}\right.
$$

For objective (2) of capital recovery it has to be recognized that capital is bound in terms of cows. Cows are bought and sold (prices are for cows $\mathrm{p}_{\mathrm{i}}$ ) and there is loss (buying milking cows and selling meat) as interests of money. Moreover, labour costs are paid at market rates. It is assumed any larger farm is no longer a family farm, rather it takes labour as hired labour. Unit cost per litre of milk are determined by purchases of concentrates (protein and carbon hydrates, partly imported, i.e. soybeans, etc., not grazing). Soon, variables have to be further specified. And we will use a production function to complement and evaluate the model.

\subsection{Animal Value (Friendly) Farms}

For the second sector (AVF strategy: animal friendly, but not necessarily organic farmer) a target ( $\mathrm{v}_{\mathrm{a}}$ constraint) for value is introduced. Hereby we get behaviour and goal functions simultaneously. The delineation is both descriptive and prescriptive, i.e. as we work with strategies and not naively with profit maximization. Note the target "animal value" as given lactation (life expectancy) multiplied with a (shadow) price of cow in numbers is individual. We can internally derive shadow prices so that the value is endogenous. It works like a commitment. It is an indirect valuation since the parallel first objective is income and shadow price analysis is a way of combining economic targets by valuation. The retrievable value of animal welfare improvement of farm is understood as the number of cows (on average) multiplied by years of lactation, and the shadow price of cows gives a type of capital assertion similar to land value. In this regard it is postulated that an AVF seeks to receive the highest value for his scarce animals in the long run as compared to income maximization (above). Again, in order to decide best it makes sense to have long living animals because it is a type of implicit capital accumulation; all this counts despite the fact that the farm is less productive in terms of lower milk yield. There is a double nexus: the farmer (because of constraints in capital, knowledge, land, etc.) cannot pursue the same strategy as LVF; but he sees his "cows" as value in strategic behaviour. (The underlying "making" a function of longevity as a different leverage will be presented soon.) Another implicit assumption is that internal effort, which is labouring for animal health (such as increasing grazing, practicing the use of straw instead of sludge, etc.) can increase with target $\mathrm{v}_{\mathrm{a}}$. The target (lactations) is considered exogenously given as preference; in negotiation it will be part of reference and cooperation with dairy factories (as pay-off for targets). Efforts are part of tacit targeting. Indeed, 
the implicit function is:

$$
f\left(v_{a}, e_{a}, k_{a}, l_{a}\right)=0
$$

Let us briefly deliberate what is depicted in equation (3). An explicit version (4) is a combination (burgeoning) of lactation years (by change above standard) multiplied by the number of cows (herd size); it delivers a number for a qualified "stock". A herd with many cows and multiple lactations is "better" than just getting a minimal number of lactations. Further, if we add, for example, the average market price of frequent lactating cows, a capital value appears; a cow in a herd of cows with many lactation periods is worth more than an "input" cow. Why is this target or value? (i) The number of lactations is a perceivable and anticipated target (beyond short-term product aims for milk) because a cow that lives longer is an asset (it should show low disease exposure and reflects skills and efforts of farmers: Langford and Stott, 2012). It means that the decision about lactation is explicit; not just part of a calculation retrieved from farm operation and about maximal milk sales. (ii) The target is outside "milk gains" as "well-functioning" of cow husbandry. (iii) $\mathrm{v}_{\mathrm{a}}$ is an indicator of health and wealth of animals, which is reckoned by farmers who pursue a strategy of seeing integrity in the background (Yeates, 2010). The reference is actually not one of ordinary, commercial farming.

$$
\nu_{a}=\left[l_{a}-l_{a, 0}\right] \cdot k_{a}
$$

We go a step further and postulate that the number of lactations can be influenced by special efforts "e" (i.e. in general working for animal health) and grazing "g" (i.e. in particular offering better foraging). These two options to stimulate effort and grazing are the outcome of an overlapping feature to reach improved "value of animals" (5). Efforts are planned and conducted by those farms which are willing to devote labour to animal welfare. As will be discussed, it is their strategic "interest" and it can be expressed in bargaining with processing firms (below). This releases us from directly conveying lactation numbers to citizens (WTP); the industry will rather have a set of payment criteria which is easier to handle.

$$
v_{a}=\left[\tau_{a, 0}+\tau_{a 1} e_{a}-\tau_{a 2} y_{a}-l_{a}\right] k_{a}=k_{a, 0} \boldsymbol{l}_{a}-\tau_{a 1} \boldsymbol{k}_{a, 0} \boldsymbol{e}_{a}-\tau_{a 2} \boldsymbol{k}_{a, \mathrm{o}} \boldsymbol{y}_{a}-\boldsymbol{l}_{a, \mathrm{o}} \cdot \boldsymbol{k}_{a}
$$

As a consequence, in bargaining, vice versa setting targets can improve the situation if grazing and more efforts apply. The scope for high lactation numbers is family labour which we presume is available but not actively incentivized so far. In our opinion AVF want to be better in caring, but it must be sponsored. Sponsoring is compensation of additional costs (for efforts) which shall work as incentive. In modelling the target can serve as first indication (observed behaviour) of a more general "preference" outline. Outlining a response to incentives which shall culminate in improving the $\mathrm{v}_{\mathrm{a}}$, is possible by programming and generalizing towards a farm model (below).

For a more general, sector approach: lactation averages, at farm level, can also be deployed as a performance index. By the multiplication of achievements beyond a reference we get a type of volumetric of qualified farm successes. Firstly, it is believed that the type of farmer (AVF) subjectively has the will to meet the target and then optimizes accordingly. This may suffice for modelling behaviour towards revealed preferences (Sen, 1973). However, beyond technical aspects of modelling preferences (including trade-off aspects, in this contribution capital formation and animal welfare by understanding farmers are trade-offs), it is opportune to believe that the target corresponds with strategic beliefs (above); so it is subjective and objective as a synthesis. The "value" of a herd as composition of average lactation per cow and size (number of cows) is expressed on the basis of effort and practice in a long-term "view" (vision). For a vision it may include having breeds fitting to AVF farming systems (Oltenacu and Algers, 2005). Challenging LVF belief, an argument for the strategy is: strategies are not expressed in a purely monetary way; rather it can be argued that they have to pay off in a changing world in the long-run and that accumulation of animal capital is a mean to assure survival of AVF farming (or shift towards). AVF pursuing the target of animal welfare may answer: his rearing strategy aims at sane cows and he cannot afford to always buy new heifers and for him it is a way to survive. For applied reasons we take that as a given.

Then, for the moment in modelling (below), we follow up with a short-term objective that complements the target. It is still assumed that AVFs are interested in yields and herd size, but in a different way compared to LVFs and labour matters. Opportunity costs are labouring hours at wage w (mainly for forage production). For instance, labour is devoted to a specific forage production, i.e. grazing, hay making, etc. Farmers seek to obtain the equivalent of a salary for efforts per hour which runs equivalent to non-farm occupation, though it differs (is lower). Looking at returns from farming at labour basis (from own labour) it has to acknowledge that concen- 
trates can be (are) substituted by grazing. Grass (hay) is costly (using own labour for production of forage at farm) vice versa survival is by having less expenses. In cases of small farms most labour is used for on-farm forage production such as grass, hay, etc.; not silage and cow diet is different from that of LVF. In fact, a whole set of making "good" food for animals has to be appreciated. In terms of model design: lactation periods "l" depend on forage produced at farm. The AVF sector has a comparative advantage by using as much roughage as possible to get healthy cowsand especially cows which shall become easily conceptive (their metabolism is not stressed due to energy need of grazing) matter. (For applied aspects, another mode to increase value is to rent out land to the productive commercial farm.)

$$
\begin{aligned}
& \operatorname{Max} \pi_{a}=\left[p_{a}^{m}-c_{a}\right] \cdot y_{o} \cdot l_{a} k_{a}-p_{a}^{f}\left[\boldsymbol{s}_{a}^{d}-\boldsymbol{v}_{a} g_{a}\right]+\boldsymbol{r}_{o} \cdot \boldsymbol{h}_{a}+\lambda_{a, t}^{*}\left[\boldsymbol{e}_{a, t}^{*}-c_{a} \boldsymbol{e}_{a, c}-w_{a} \boldsymbol{e}_{a, g}\right] \\
& \lambda_{a}\left[\boldsymbol{v}_{a}-\boldsymbol{k}_{a, 0} \boldsymbol{l}_{a}+\tau_{a 1} \boldsymbol{k}_{a, 0} \boldsymbol{e}_{a}-\tau_{a 2} \boldsymbol{k}_{a, 0} \boldsymbol{e}_{a}+\boldsymbol{l}_{a, 0} \cdot \boldsymbol{k}_{a}\right]
\end{aligned}
$$

Compared to the previous objective (of LVF), own labour plays a critical role in terms of not being included in the gross margins; rather there is a family labour constraint. Additionally, land can be rented out and saving of concentrates in terms of grass equivalents is a gain. In both objective functions (AVF and LVF) costs are minimized because they shall serve to establish negotiations by being interest functions rather than representing detailed decisions. We will present incentive schemes after having discussed bargaining issues.

\section{Leveraging and Production}

At this stage it is important again to notice that our modelling is firstly intended to serve the identification of responses of farmers to strategic behaviour and incentives. Secondly, modelling shall serve to get insight into modification of behaviour through contractual interacting with market partners (dairy industry) and the state in the interest of animal welfare. Since the focus is on leverages and leverages are understood as opportunities to increase returns from property, inputs are thereby added through transacted goods. (Note in finance "own" capital is leveraged by borrowed capital, yet to increase returns on own capital). Here in concentrated form animal feed leverages if bought. The background is a depiction of scope. Finding scope for leverage at modelling level is in fact a layer of scrutinizing behaviour. Its contribution is not that leverage goes into genetics, husbandry and feeding, but that genetics supports leverage. LVFs see leveraging and it is modelled as an inverse function. We postulate: there is a relationship between yields (genetics), herd size and lactation years as well as intensity of land use following leveraging. Besides we shall keep in mind that the analysis requires variables of cooperation for competing sectors of milk farming. We start with commercial leverage.

\subsection{Description Variables Describing Commercial Production}

At the level of revealing a relationship between intensity of farming on the one side and land use, milk yields and soybean use on the other side, our first equation (7) of leveraging for LVF envisages a technology frontier (practices). It is an inverse function and represents leverage options in dairy farming used by conventional farmers, here to get as much milk per hectare from scarce land. I.e. farmer's own resource, land, is "scarce" and capital accumulation can be best obtained and extended through purchase of concentrates. The aim of leveraging is to have as many cows as possible per hectare and this will give a maximum of milk at economies of scale. Equation (7) explains intensity (cows per ha, truly reverse ha/cow: a/k) as dependent on use of soybean per cow, grassing (roughage) per cow and envisaged milk yields.

$$
\left[a_{c}+a_{r}\right]_{c} / \boldsymbol{k}_{c}=\omega_{c 01} /\left[\omega_{c 10}-\omega_{c 11} s_{c} / k_{c}+\omega_{c 12}\left[g_{c, 0}^{d}+g_{c, r}\right] / k_{c}-\omega_{c 13} y_{c} / k_{c}\right]
$$

For instance, if, in the frame of equation (7), more soya-beans "s" are used $\uparrow$ (as negative factor and reducing the value in the denominator), the denominator will decrease $\downarrow$; yet intensity increases $\uparrow$, vice versa, and the right hand side will decrease $\downarrow$ (inverse function). Furthermore, since we are interested in effects of intensity, it means that more cows are (can be) reared per hectare, saying that intensity increases which makes the left hand side smaller $\downarrow$. (This is what should be expected.). Function (7) delivers the leverage effect. For any further optimization we actually need first derivatives to show the behaviour of farmers based on leverage. Further, the number of cows has to be translated into milk. Perhaps, in the frame of a typical production function, we can further state a function of declining productivity of cows.

$$
\nu_{c_{c}}=\omega_{c 3} \sqrt{k_{c}}
$$


It is the number of cows and cows deliver volumes $\mathrm{v}$ of milk; but by increasing the number of cows the productivity per cow declines. (Note there is always the issue of average yields and marginal yields in production economics; so we presume that conventional farms can expand production; though a linear production function does not apply well.) What are the implications for modelling? For the moment (in notification) we state area per cow ('a' is area/ cow and variable) is contingent, i.e. we declare relative intensities for reasons of simplicity:

$$
\left[a_{c}+a_{r}\right]_{c}=\omega_{c 01} /\left[\omega_{c 10} k_{c}-\omega_{c 11} s_{c}+\omega_{c 12}\left[g_{c, 0}^{d}+g_{c, r}\right]-\omega_{c 13} y_{c}\right]
$$

By this change the above objective (2) can be re-written as (2'); here as product of area multiplied by the constituting returns from cows we use a Lagrange representation of constraints:

$$
\begin{aligned}
& \max \pi_{c}=a_{o}\left[[1+\rho]\left[p_{s}^{k}-p_{p}^{k}\right] \boldsymbol{v}_{c}-\left[\left[p_{l}^{m}-c_{o}\right] y_{c} \cdot \boldsymbol{l}_{o} \cdot \boldsymbol{k}_{c}-c_{s} \cdot \boldsymbol{s}_{c} \boldsymbol{k}_{c}-\boldsymbol{r}_{s} \cdot \boldsymbol{w}_{s}-c_{o}\right]+\lambda_{c}\left[\boldsymbol{t}_{i}-\sum[1-\boldsymbol{v}]^{t}[\right.\right. \\
& \left.\boldsymbol{r}_{i o} \cdot \boldsymbol{a}_{i} \boldsymbol{k}_{c}+\left[\boldsymbol{r}_{o}-\boldsymbol{p}_{l}\right] \cdot a_{r i} \boldsymbol{k}_{c}+\boldsymbol{c}_{0 i}\right]+\lambda_{l}\left[a_{t}-\omega_{c 01} /\left[\omega_{c 10} \boldsymbol{k}_{c}-\omega_{c 11} \boldsymbol{S}_{c}+\omega_{c 12}\left[\boldsymbol{g}_{c, 0}^{d}+\boldsymbol{g}_{c, r}\right]-\omega_{c 13} y_{c}\right]\right]
\end{aligned}
$$

Then for (2') we can take first derivatives (as equation 8); it is an optimization of a specified objective for leverage. We receive optimal values for soybean use and grazing represented by

$$
\begin{aligned}
& {\left[p_{s}^{k}-p_{p}^{k}\right]-\left[p_{l}^{m}-c_{o}\right] \cdot y_{c}+\lambda_{c} r_{i o} \cdot a_{i}+\left[r_{o}-p_{l}\right] \cdot a_{r i}} \\
& \left.-c_{s}\left[\omega_{c 10}-\omega_{c 11} s_{c, 0}^{d}+\omega_{c 12}\left[g_{c, 0}^{d}+g_{c, r}\right]-\omega_{c 13} y_{c}\right]\right]=\lambda_{c} \omega_{c 01} k_{c} a_{t}
\end{aligned}
$$

As can be shown, the Lagrange variable is the same as the land price and a demand for soybeans and grass is based on the link giving area and yield, which is determined exogenously.

Yet we work with the inverse and (by optimization) get linear conditions (9) for an optimum on concentrate feeding and number of cows. In the example (9) it is stated that soybeans impact on land intensity (vice versa an increase in the number of cows per hectare); grass is the opposite and milk yield increase (propensity). The aim is delineating a number of cows per hectare. Then we have to supplement the quantified relationships with other marginal conditions resulting from optimization (by modelling, through a correlation between milk yields and soybeans to get enough protein and energy in cows is depicted). For lactation periods:

$$
\left[y_{c}-\omega_{c 21} S_{c}\right]=\omega_{c 20}-\omega_{c 22} l_{c} \text { and } \boldsymbol{l}_{c}=\omega_{c 20}-1 / \omega_{c 22} \boldsymbol{y}_{c}-\omega_{c 21} \omega_{c 22} \boldsymbol{S}_{c}
$$

it is found that they depend on milk yields and concentrate use. Equation (9) says that an eventual milk yield gap (deficit of inputs vs. outputs) can be boosted by more soybeans and this decreases the number of lactations (vice versa). The farm lobby will doubt this to a certain extent; but empirical evidence supports the inference (see above for a discussion on animal health and striving to get higher yields, Ingvardsen et al., 2004). Our optimization logic supports evenly the negative externality hypothesis that cow life expectancy is impeded. Then we have to further involve labour and look at a way of obtaining grass as forage. Grass production is a limitation in the production process and the aim is to avoid costly labour. Again, to make things not difficult, labour costs are linked proportionally to cows. It is postulated that, at a minimum, a percentage in unit costs for milk is labour cost. Costs are determined by number of cows and cows are fed by maize. Maize " $\mathrm{m}$ " is roughage without outside grazing. So, if we have optimal foraging composed of maize, grass and concentrates we get $\mathrm{k}$ cows:

$$
\boldsymbol{k}_{c}=\omega_{c 21}\left[\boldsymbol{m}_{c}+\boldsymbol{m}_{r}\right]+\omega_{c 22} \boldsymbol{g}_{c}+\omega_{c 23} c_{c}
$$

Besides, roughage use per cow and own land as well as additionally rented land our farm is farmed by hired labor.

$$
\left[g_{c}+\boldsymbol{m}_{c}+\boldsymbol{m}_{r}\right] / \boldsymbol{k}_{c}=1 /\left[\boldsymbol{\omega}_{c 40}+\boldsymbol{\omega}_{c 41} \boldsymbol{w}_{r} / \boldsymbol{k}_{c}+\boldsymbol{\omega}_{c 42} \boldsymbol{l}_{c r} / \boldsymbol{k}_{c}\right]
$$

Equation (11) shows that there is a trade-off in intensification. If farmers want to deploy more cows on rented land, it means more hired labour; more farming on rented land will increase labour costs; yet lactations are also in equation (11). Labour is hired at wage prevalent in a region and payments are totalled and residual; own labour is keen to management only.

\subsection{Description Variables in the Case of Animal Welfare Production}


For AV-Farmers who seek to maximize the value of a cow herd as constraint (measured as target multiplied by internal shadow price, see above), i.e. besides income. The success of this strategy is influenced by an assessment of scopes in actually getting long-lived cows. We may presume that AVF have discovered a "similarity" for leveraging like LVF, but now for a scarce cow herd setting. Feasibly prevails as conditionality and as before (leverage), but now for number of lactations. It shall link effort and grazing to life expectancy in a positive manner.

Compared to LVF we must seek different reasons for behaviour. One alteration is matching the type of labour (effort here defined as physical labour of smallholders) and caring for animals; this is to say, farm labour. The other issue concerns the realisation of leverage through practice. It might be that grazing instead of soybeans has some economies of scale which are outwardly an effect of skills. The issue is to get appropriate labour use per cow. We postulate leveraging with respect to grazing; i.e. if effort decline happens farmers adapt to grassland use at a larger scale. On the other hand, if farmers want milk yields getting similarly high to the ones of LVF, this increases the effort per cow significantly; the same applies to life expectancy.

$$
e_{c} / k_{a}=\omega_{a 10} /\left[\omega_{a 10}\left[g_{a}-\omega_{a 1 s} s_{a}\right] / k_{a}-\omega_{c 12} l_{a}-\omega_{a 13}\left[y_{a}-y_{c}\right]+\omega_{c 10}\right]
$$

From this condition it is retrievable that effort assessments per cow are a function of grassland use as well as life expectancy. We postulate that grazing presents a health practice. This has effects on forage and land. Additionally we recognize a reference for grazing as standard.

$$
g_{a}=\omega_{c 12}\left[a_{a}-a_{r}\right]
$$

One aim, as said in leveraging, is nonetheless to maximize income, but under auspices of long-term animal welfare. Integrating this secondary goal (target) into the objective function, similar to the above outline, behavioural equations can be derived; yet we have to link it to incentives.

\section{Bargaining}

\subsection{Market Interactions and the Creation of Interest}

So far the objective functions and potential behaviour of different farmer (types, strategies) were explored under the notion of market transactions for milk and forage. Now, to get a bargaining model which shall be used for policy analysis, it must be made clear what the gains (variables) of co-operation are? It also has to be clarified which compromises are to be explored; respectively if there are scopes for intensifying and participating. Hitherto, references for bargaining must be explicitly constructed as behavioural change oriented and they must include definitions (settings) of property rights. Note that everything depends on explicit property structures. Vice versa this means that a policy redesign for bargaining depends most of all on acceptance and obligations; perhaps there have to be pre-rights which are established in favour of animal welfare and which force LV-Farmers (i.e. those farms that have animals with a low life expectancy) to contribute to the economic success of the sector. Some AV-Farmers who are in favour of higher life-expectancy need more compensation (payments), some less. To dig deeper into issues, let us firstly find out what is a threat? and why there is a will to cooperate? The analyst needs to know whether there is common ground between actors on rights and threats. In our modelling, as derived from the problem statement, it was said that citizens may have a WTP for animal welfare. A WTP, in the eyes of economist, is, ceteris paribus, a feature of preferences and purchasing power for standards. As part of consumer behaviour it depends on the design of goods (branding) offered within specific characteristics. For us, "more lactation periods" should specifically enable marketing of milk at higher "quality", but most likely has to be translated into more visible criteria. Arguing normatively, some consumers may pay (a good price) for "better" milk products, but only if they see practices changing. This will increase competitiveness of all farmers who commit themselves to animal-health oriented farming and, perhaps from the perspective of finding private regulations, minimal governance is enough, i.e. WTP is o.k. and releases the government from its duty of interference. For this we host a dairy industry and look for private action. 


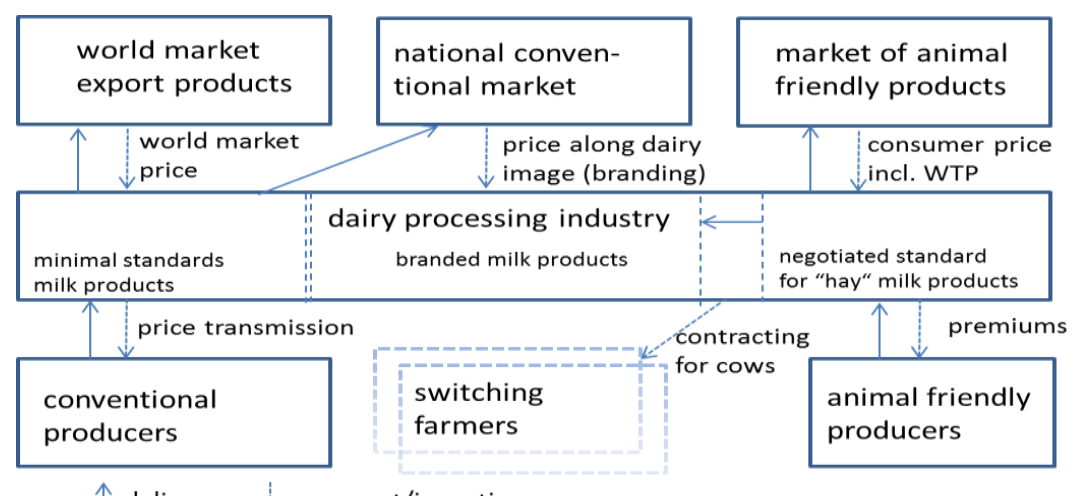

Figure 1. Market Structure

This is to say that many economists would think that firstly private activities should solve the problem because informed consumers may choose the "right" products and problems are solved spontaneously. But how do they know? Choice modelling is insufficient if there is no actor which sets standards; alternatively formulated: who will optimize for life expectancy based on WTP (in consumer's eyes). Will WTP have any impact on farm behaviour in practice? Is this a vicious cycle? The author thinks that "the market will do it per se" is too narrow, because the aspect of initiation and standardization is missing. If more consumers/citizens decide to buy milk products from AVFs (apparently beyond a threshold) this should have implications for the market and system level. There should be a shift of demand and this ought to have an impact on market structure and performance (perhaps not on world market, but on local markets). We postulate: in a competitive world, in terms of threat, the industry may fear to loose revenue from conventional markets. Especially fresh milk markets can be impacted, i.e. if a bigger number of consumers divert to animal friendly products, a shift comes in WTP and price. Perhaps improved products will result in lower returns for LVF if demand for them declines: this is a threat and the overall image might be a trigger. Here, we can identify willing (trigger) to bargain against threats. (i) A new equilibrium between prices (mark-ups above original milk) should prevail in favour of labelled milk from healthy cows. Stating WTP (price gaps, assuming consumers have WTP for milk produced along animal welfare standards, i.e. hay-milk), it has to be acknowledged: the market (ii) offers scope to widen the gap and (iii) there is danger to miss that. (iv) A crucial question/report for bargaining is that any participant must recognize: a compromise should deliver a positive benefit/cost ratio (under treat) and that the participant hopes he will be relieved from the danger to lose (in case he holds market shares).

(v) The issue is on what to concede and what is a threat to be anticipated in bargaining. There are two ways to anticipate threats: an immediate (for instance an implicit) threat is that conventional milk prices will sink if consumers react strongly to animal welfare concerns and a pertinent is it will be local markets (still more favourable than exports?). Another issue: can less demand, but a seeming attraction of supply in a conventional market segment reduce the number of cows (by price drops) and is this a threat for the industry? However, consumer choice is ostentatious; then the question is: what are impacts and assessments? Actually we should develop a full market model of interaction, but that is beyond our analysis. Rather let us work with imperfect markets. Farming and industry offer interaction and industrial processors decide on milk buying and prices. The focus is on threats. Will the threat of reduced revenues and margins from milk of conventional farms create an interest in switching (bargaining)? (vi) We think it will, but the question remains: is the threat sufficient to have an impact?

Initiatives for bargaining shall come from the processing industry. Communication is needed on potential effects (impacts). To analyse a threat (as vaguely existing but later factual), (i) a price effect of WTP shall be signalled and regressed on animal welfare (grazing and health index). It can be in contingent valuation style. (ii) WTP is a topic which may create some dispute on what is reasonable for consumers to be involved in (below). From marketing (Weinrich et al., 2014) at a minimum and partly already in practice, milk from cows having access to pasture and indexed practices is priced higher than the average conventionally produced milk.

$$
p_{a}^{m}-p_{c}^{m}=\omega_{a 40}+\omega_{a 41}\left[g_{a}-g_{c}^{f}\right]+\omega_{a 42}\left[i_{a}-i_{c}^{f}\right]
$$

Equation (14a) means that if one price (conventional) is bargained, the other follows accordingly in the logic of 
price differentiation and equilibrium which is determined by consumers concerned for animal welfare; equation (14a) gives the residual equilibrium price interaction. The function may look minimal and as though it is deterministic (automatically prices "must" adjust), it already tells us that an increased willingness to improve life-expectancy (of animal welfare oriented sub-sectors) will create a visible price gap (decrease the price for conventional milk). Because more citizens will recognize the opportunity in demand, conventional prices will go down. It is not only a secularistic move, but there is a deliberate choice behind it. In altered versions the complexity can rise. For instance, the relative change of the conventional price is a function of relative policy in the animal welfare business (14b).

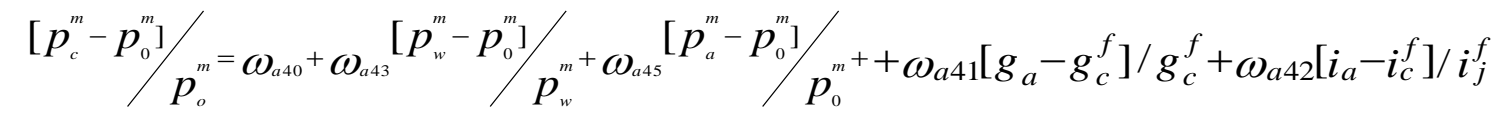

The empirical background (and as observed in (14b)) can be reckoned as a type of price transmission, i.e. if it comes to an interaction with world market prices, the adjustment is moderated through grazing and lactation of AVF which makes a contribution for the image of the dairy and brand. In terms of property rights, to verify the threat: what is valuable interaction? It looks as if the LVF sector should avoid strong deviation from good practices. (iii) The issue is: if too many farms become commercial, this will raise the gap (large gaps reduce milk production in LVFs). Keep in mind that the industry's strategy to always sell milk for good profits (not low price see below). International business has low margins. Having more as an animal friendly farmer may be tricky. In the hands of the conventional sector we see an element of joint perception of performance for the whole sector. Otherwise, there is a danger of losing consumers. To keep citizens'/consumers' WTP is a tricky thing. An added aspect is that competitive milk pricing on international markets allows only minimal deviations for animal welfare. It looks as if prices cannot be influenced; but looking at scarcity, the conventional sector can have a stake in good images. (iv) A narrower gap will make a price decline in a less pronounced way, yet enough to offset profit losses. We work with the above representation and reference. However, before we take a stand we have to work on industry interests.

\subsection{Dairy Processing Industry's Interest}

So far, objectives and system constraints were introduced first. Then we looked at representative farms and their strategic behaviour. Now, the analysis should be sector oriented and include the dairy industry as "mediator". The industry sets variables for negotiation themselves, and incentives for animal welfare are results of interactions and performances of partners. Effects and results can only be partly specified exogenously (as regulations) because they are endogenous, and "full health" is a mystery; so we introduce negotiation. To analyse, we propose a triangular bargaining model in which conventional farmers, animal welfare oriented farmers and a dairy industry will find conditions for contracts in practice (animal welfare); yet in a game including power. The word "power" still does not exist in usual economics (only supply, demand and equilibrium). We need it to understand contracts. Additionally, money from consumers for labels of milk from AVFs looks like a solution, but money and labels for what? We see the industry in charge to offer a scheme on product differentiation and practices. Firstly, the scheme will be presented and secondly a fourth player, a "government", will be addressed. Additionally, we will also have to clarify what private and public interests are.

\subsection{Objective Function of the Dairy Processing Industry}

As a readymade step for bargaining we have to explicitly establish the objective function of a dairy processing unit. It shall aim at the inclusion of animal welfare (life-expectancy and grazing, yet as a feature in marketing for acquisition of milk at higher prices; for example of hay milk products: kaeserebellen 2018). A question is: is the industry interested in animal welfare? Most likely not per se, but it is instrumental for improving cash flow. Specifically promoting milk products with animal health claims (grazing, "lactations", etc.) revenues shall increase. We have already supposed that a dairy company can process milk from conventional farms as well as welfare oriented farms. Products become differentiated and the image of the company improves with more animal friendly milk: its labels sell better. But additional processing variants (different lines) create costs and it requires costly marketing. In principle, there shall be three options: (i) world market, (ii) national market (both conventional) and (iii) solely animal welfare oriented for those consumers with WTP. From all sales types the industry receives revenues along volumes. Prices, marketing, costs, and incentives differ. In modelling gains (net values from cooperation) corrected returns per litre minus farm gate price matter as margins. For coverage of interest we need active milk pricing, per litre costs and any margins of milk products. Yet we simplify. We start with the world market. It is suggested that fat and protein (as major components) determine the value of sale and hence products with different fat (butter) or protein (skim milk powder) can be valuated along ingredients as percentage. (Cheese is an example for both). In summary: at world market scale a fixed "milk" price (for 
products) prevails and volumes are translated into tons of sales and then into the number of cows. It serves as a reference. In principle the world market price is the marginal revenue guide (as in conformist agricultural and market analysis). It guides the dairy for total marginal costs. The world market (gross margins, obtained from trade on international markets) is price-wise competitive. Besides that, the local market allows some price variation by products, while the size of a dairy operation is determined by the world market condition.

\subsection{Joint Costs and Reduction of Parameters}

To further describe interactions of markets and functions (such as allocating resources, land, to AVF) as well as channelling WTP for animal welfare (being engaged by the processing industry; here it is a unit of calculating references for marketing opportunities of farmers), joint cost calculations of processing milk and selling supplement the analysis. For modelling the marginal costs are assumed to be linear. (We assume a linear marginal function as supply function in depicting overall processing costs; furthermore, we want to obtain marginal costs equal pricing, i.e. a pricing equivalent for raw milk.) Then, costs are quadratic (15). Anyway, many authors would think it is economies of scale which determine operation capacity. We argue with short-term costs which depict the usual supply curve (up-right-hand in a market figure 1). It is assumed that supply shows certain elasticity to price increases, determines capacity, and we can deploy linear supply responses which are a revelation of quadratic costs (functions). For example if we methodically calculate costs/revenues (by fused margins at market volumes $v_{i}$ ) the overall cost and benefit for the processing company can be calculated. We start with the generic assumption that margins are the interest of the industry, so we postulate:

$$
\pi_{d}=\left[p_{w}^{e}-p_{c}^{m}-c_{c}^{m}\right] \mathcal{V}_{w}+\left[p_{c}^{s}-p_{c}^{m}-c_{c}^{m}\right] \mathcal{V}_{c}+\left[p_{a}^{s}-p_{a}^{m}-c_{a}^{m}\right] \boldsymbol{V}_{a}-\omega_{a 43} \mathcal{V}_{t}-.5 \omega_{a 43} \mathcal{V}_{t}^{2}
$$

Profit is stated as milk volumes per market segment $v_{i}$ and, apparently the objective function (15) has to be amended to include incentives (payments) as well as image and promotion aspects. A first step is to make market shares active and link them to cows (volumes of business perceived from the famer side) as well as to reduce the number of variables, primarily to link them and next to put them in bargain. A balance check of milk gives processing costs in bulk:

$$
\begin{aligned}
& \boldsymbol{v}_{w}+\boldsymbol{v}_{c}=\boldsymbol{y}_{c} \boldsymbol{k}_{c} \\
& \boldsymbol{v}_{a}=\boldsymbol{y}_{a} \boldsymbol{k}_{a} \\
& \boldsymbol{v}_{t}=\boldsymbol{v}_{w}+\boldsymbol{v}_{c}+\boldsymbol{v}_{a}
\end{aligned}
$$$$
A v_{i}=I k_{i} \Leftrightarrow v_{i}=A^{-1} \boldsymbol{I} k_{i} \Leftrightarrow v_{i}=\Xi k_{i}
$$

From this balancing statement we receive a modified statement (inverted matrix in front of the endogenous variables) which gives milk procurement (sold in market segments) as cows in conventional and animal welfare farming as well as total milk processed in the dairy company.

$$
\begin{aligned}
& v_{w}=\xi_{11} y_{c} k_{c}+\xi_{12} y_{a} k_{a}+\xi_{13} v_{t} \\
& v_{a}=\xi_{21} y_{c} k_{c}+\xi_{22} y_{a} k_{a}+\xi_{23} v_{t} \\
& v_{c}=\xi_{31} y_{c} k_{c}+\xi_{32} y_{a} k_{a}+\xi_{33} v_{t}
\end{aligned}
$$

This new notation about volumes $\mathrm{v}$ of milk: along t total, c conventional and a alternative becomes a core for negotiation as farms add or reduce cows served by dairy. The underlying idea (in terms of structuring the dairy industry's position) is to achieve a negotiation on the number of cows in sectors and pricing which is constructed as an incentive scheme (below). It makes the profit of the dairy industry a function of the number of cows in each sector (market share) and volume of total milk (cost). Further we can introduce special marketing costs. We would like to express the profit function in terms of cow numbers because it gives an indication on the degree of proliferation of AVF dependent on incentives as well as outlines the strategic position of a particular dairy. Moreover, we postulate that maximizing the objective function (15) towards the total volume of milk is in favour of the dairy industry.

$$
\pi_{d}=\left[p_{w}^{e}-p_{c}^{m}-c_{c}^{m}\right] \xi_{11}^{*} k_{w}+\left[p_{c}^{s}-p_{c}^{m}-c_{c}^{m}\right] \xi_{12}^{*} k_{c}+\left[p_{a}^{s}-p_{a}^{m}-c_{a}^{m}\right] \xi_{13}^{*} k_{a}-\omega_{a 43} v_{t}-.5 \omega_{a 43} v_{t}^{2}
$$

So far the interest is coarsely defined as getting different (better) prices in local and hay milk channels. Yet for that we lack incentive instruments (developed below). However, incentive schemes have to be presented before 
finding a common ground. We have to especially channel the abovementioned WTP and look at its effects in the system. To do so we argue with different types of pricing; types shall sufficiently express the power of the dairy industry and work for clients. (i) It implies world market prices may not be transmitted in full; rather, having deducted unit costs, LVF receive only a negotiable percentage of the residual (less $100 \%$ ).

$$
\boldsymbol{p}_{c}^{m}=\boldsymbol{\alpha}_{1}\left[\boldsymbol{p}_{w}^{e}-\boldsymbol{\alpha}_{\mathrm{o}}\right]
$$

This formula works in case of imperfect markets and signifies the world market price is only partially transmitted. Price transmission is a control variable for the industry and as dairies are mainly cooperatives, the management has power to modify pay-out or can retain profits and share by dividends. Here through dis-incentives for LVF that can work. In fact, revenue and cost outlays of dairy firms (in export) need to be specified; using cost function above, the parameter $\alpha$ is a core instrument of letting the conventional farmer participate in trade less than before.

(ii) In contrast to LVF, a mechanism must be envisioned for the AVF, which is not based on an exogenous market but rather on an internal gratification (bonus) system. It shall recognize and reward changes in practice. Due to higher consumer prices which can be retrieved from conscious consumers, farmers could simply expect a higher price for milk, yet meet additional costs. But that would not be a targeted system for animal well-being. Bargaining power shall play a role, the industry will be asked for a "fair price" and offer assure "service"; notably life-expectancy. The negotiation is not free of standards to be negotiated in parallel. Usually, in negotiation analysis or monopoly and oligopoly decision, interacting markets work along trade-offs (Zusman, 1989). There is a price-quality (standard) constraint to be checked in negotiations. In that respect we may have a type of individual "monopsony" as reference, i.e. a dairy firm knows consumers' WTP, specially, for various practices (standards for WTP), but only transmits a percentage to farms for their own sake. Then the procurement price from animal friendly farmers AVF is a matter of acceptance, i.e. it is negotiable in conjunction with animal friendliness as service levels. We assume: there is limited transparency and the industry can hide benefits (prices achieved) behind costs. For instance, it will argue for a need of separate treatments, higher costs per unit, more labour, etc. For this, conceptually, the industry needs to know "supply" functions based on standards and costs. To a certain extent one can approximate a principle-agent-frame. To re-iterate: consumer WTP which can be obtained depends on animal welfare levels. For modelling let us assume, pasture (grazing) area/cow and live-expectancy are part of WTP (can be derived from a willingness to pay analysis).

(iii) To further explore: pastures as sources of forage and life expectancy (number of lactations and yields or feeding) are endogenous decision variables for an AVF, but contingent on an interactive incentive scheme. The interactions between number of cows, grazing and life-expectancy (as decision variables) can be further elaborated in terms of prescribed practices. Alternatively, it can be supposed that, according to knowledge, an incentive constraint function is given and only payments are requested (to sustain business). For given practices, payments shall be dependent on negotiated (variable) standards and serve as incentive and not gratification. For modelling (proposing a standard, which for example dependents on reduced milk yields, improved grazing, life expectancy, etc.), it is a response of AVF; is it sufficient? The dairy industry, vice versa, learns behaviour, although it only wants money. On the other hand, it might be argued by animal welfare groups (Harvey and Hubbard, 2013) that grazing and lactation are only limited criteria and not enough. The question arises if they are all consumers' want? However, in many studies on consumers'/citizens' WTP (about farming practices, Nocella et al., 2010) it was shown that it is really difficult to communicate complex standards and that consumers might agree on such simple things that one even finds in models. In practice, for instance, images can help and we can find (correlate) images with WTP. In the introductory part, the argument was also (primarily) on life-expectancy; but is it really visible? We still argue with it and list practices, for example: (i) share of grass in forage (health), (ii) additional labour input (because grass procurement needs more labour) and (iii) land-animal ratio (expressing manure practices), etc. In the end, these practices are strongly correlated with life- expectancy. In the context of real messages (statements on practices and WTP) it might become thorny to get exact linkages between practices and WTP. In the current contribution we focus on grazing and concentrate on life-expectancy linked to visible key practices and on life-expectancy as implicit standards. Grazing is clear on both sides. It is an already established criterion (EU, 2016; milk from grazed cows) and concentrates are minimized, for example, for hay-milk. Indeed, there is interaction between grazing, haying and labouring for life-expectancy. Consumers (in promotion) are probably easily convinced by seeing cows on pastures (images), so we go for that.

Further note: at the WTP level (about investigation in attributes for healthy cows usually done by marketing: Weinreich et al., 2014) a much more differentiated outcome of criteria may not be attainable in the case of AVF 
milk products from then "healthy" cows, but costs prevail. No perfect market exists in equilibrium by default. The dairy industry holds information and farms receive discerned payment. In reality a complex pricing formula for milk must be made practical. There is a need for a formula which allows adding a bonus to basic pricing (add-ups) and discerned services. Right now we assume a bonus is sufficient to specify the bargain.

\subsection{Setting Parameters}

For our modelling we seek a simplified version in which the contingency on practices is explored, at least at the level of parameters. In a mode of finding a combination of variables for visible services, two versions are possible: an index of parameters (grazing, lactation, yield reduction, etc.) or (a) key parameter. In this contribution we prefer the key-approach because it is more illustrative and easier to handle. Our key variable (parameter) is firstly life-expectancy which represents animal health more accurately than any veterinary report. It means that we will use a stated link between pondering categories for animal health and long-term improvements in the performance of dairy (cows). Note that the focus shall be on life-expectancy as information and on giving a bundle of linked activities, though payment shall be operational. The problem is that optimized behaviour for inputs and practices depends on output as service (bonuses based on WTP) and input (costs compensated) as well as on labour (seeking better monetary returns for AVF, see above). Attributes in WTP of consumers, in fact, are mostly not stated in the same manner as farm performances. So issues like "which practice creates a bonus cannot be answered directly. To address issues (in terms of bonuses) farmers behave differently and are willing to contribute by indirect combinations; yet they say they need to know which practice is rewarded and at what amount of money. This paper argues that "better health is lactation numbers". Trying to minimize tension in bargaining, dairy industry and farmers might agree on life-expectancy surrogates. Then receiving a premium expressed for cows, rewarding can be scored in joint approval. It changes the objective function:

$$
\pi_{d}=\left[p_{w}^{e}-p_{c}^{m}-c_{s}^{m}\right] \xi_{11}^{*} k_{c}+\left[p_{c}^{s}-p_{c}^{m}-c_{s}^{m}\right] \xi_{12}^{*} \boldsymbol{k}_{c}+\left[\left[\boldsymbol{p}_{a}^{s}-\boldsymbol{p}_{a}^{m}-c_{a}^{m}-\pi_{a}\right] \boldsymbol{k}_{a}-\omega_{a 43} \boldsymbol{v}_{t}-.5 \omega_{a 43} \boldsymbol{v}_{t}^{2}\right.
$$

Additionally: $\pi$ : premium (bonus for change of lactations and grazing)

Again, on the logic for premium response we follow the producer's concern to get a premium which stipulates a farmer to produce milk from cows with more no. of lactations and we also include a lump sum for grazing. I.e.: (i) in the objective function of AV-Farmer (6) we state parallel that a bonus above the conventional price will create incentives. How can we relate the bonus (presented incentive momentum) to practice? Yet the function (17) includes a milk price which is upgraded by lactation numbers and the bonus would add to conventional milk prices. The farmer would like (needs) a combination of appreciation of lactation years and milk price to compensate for the higher levels of effort. The bonus part of payment in detail then is:

$$
\left[p_{c}^{m}+z_{a}-c_{a}\right] \cdot y_{o} \cdot l_{a} k_{a}=\left[p_{c}^{m}-c_{a}\right] \cdot y_{o} \cdot l_{a} k_{a}+z_{a}^{l} \cdot y_{o} l_{a} k_{a}
$$

This type of incentivizing by bonus $\mathrm{z}$ (as part of objective function (6+)) is driven by behavioural inspection of AVF from the perspective of an industry which tries to positively change behaviour. In the vein of acknowledging that life-expectancy is an underlying capital concern, it is "fine". In fact, using a behavioural constraint (as introduced) which links yields, life-expectancy and grazing, will enable a negotiation on incentives (bonuses) and services (improved standards with the core of increased life-expectancy as accepted). As has already been noted, life-expectancy and lower yields are eventually topics not understood by consumers, but grazing (milk produced by cows which primarily graze) is! Negotiations cannot be introduced at any criteria; but we further suggest (below) moving to grazing in percentage of forage as prime, as an easily communicable criteria. The idea here is to get calculi right.

\subsubsection{Animal Value Farmer}

The essential problem for making the bargain operational is that pricing (WTP) by consumers and payment (WTA) to farmers (service by farmers) should be based on criteria that are close to each other. Bargaining can only be operational and effective if one works with reduced complexity. In modelling and reality (yet, mostly to enable calculations of pros and cons as well as gradual adjustments of parameters) few variables are at the maximum, at best only one. However having worked on "own labour" (above), some words are needed. We are not native and see labouring for animal health as a voluntary thing; rather the indicated "animal friendly farmer" AVF also has an interest. In the given situation, a bonus is designed according to what animal friendly smallholders want as a reward maximizing income. In other words, from farmers' view of the negotiated standards (with industry), we shall apply at the lowest "lactation", while money flows "at best" (to AVF). Vice 
versa, dairy processing industries want standards (to convince consumers) and seek to transmit as little money as possible. Our communication on standards shall be equation (18a). To condense, practices shall be bundled as:

$$
\omega_{a, 1} l_{a}+\omega_{a, 2} g_{a}-\omega_{a, 3} y_{a}=\omega_{a, 4} e_{a}
$$

We suggest reducing the bargain to two explicit criteria based on practice: grazing and effort being embedded in (18a). Yet, life-expectancy is crucial but implicit behind improving practice of gazing (also as hay-milk) and labour awarding. In expression (18a) we learn that higher numbers of lactation increase efforts while lower yield expectations decrease efforts.

\subsubsection{Animal Friendly Consumer}

Parallel it shall work for the consumer. WTP by preferences which constitute the payment criteria has to be condensed (18.b) which can be negotiated. We suggest elaborating on both (18a and b, realizations) which is weighted practices appreciated by consumers and farmers. It is inferable, gives wish and appreciation of consumers concerning animal friendly farming, yet in the niche market of milk products (called, for instance, hay milk). Using it as index, we can vice versa translate the consumers' will into the price increase foreseen by the dairy industry.

$$
\omega_{c, 1} l_{a}+\omega_{c, 1} g_{a}+\omega_{c, 1} y_{a}=i_{a}
$$

The index serves the dairy industry to get the quantified price (incl. WTP). One can also see the index as representing the "image" of brand (see below). As the image has an influence on price, the dairy will be well advised to promote an increase of index and maximize assumed benefits. The construction of the dairy processing industry objective function (for bargaining) contains a parallel optimization of an optimally achieved image as a mean in promotion efforts for milk products and indexing the consumer criteria. It obtains higher monetary values from consumers. All is based on knowledge and design of standards, which is an active task of the industry. In terms of institutions we assume that owners of the industry can enforce management to become committed to the design task because it will pay off, hereby creating interests.

\subsubsection{Synthesis}

To construct (exemplify) the behaviour towards AVF, the industry has to develop a referenced position enabling bargaining in a mode which allows it to specify offers and reciprocal responses. Our representation of the problem which includes an actual designing of the interface between consumers and producers is grounded in an active role to be played by the dairy processing industry. We need to further clarify on that. Any active role must be driven by interest. For our modelling, interest is expressed in terms of a structured cooperative (game) behaviour (Zusman, 1976) which comes with the index of preferred practices " $i$ " and grazing "g" associated with milk products (branding). Both shall offer WTP (18b), i.e. on basis of "do ut des" (in which money for service plays a role). Consumers receive milk products classified (indexed) as animal friendly, and willing farmers perform with higher effort. For efforts (for example: more per unit hours for milk, associated with making life of cows better) and grazing (instead of concentrates) farmers receive "compensation". For both sides this means that the design and problem finding exercise has been worked out. From the farm practice side, grazing, milk yield and life expectancy are combined (18a); the same applies to the consumer framework (18b) which is in equilibrium. Our construction of a bargain proposal, conversely, sees years of lactation and yield reduction as being implicit, and the explicit focus is on percentage of hay in feeding practice. This has to be equated with the consumer interest. The dairy processing industry actively prepares standards communicable with producers and consumers. Perhaps this is not an easy task, because (in the perspective of coordination at a market) the request from consumers and offers from the side of the farmers should match (equation (18)). Also, secondary further information is needed on the willingness to accept increased efforts (service) for reward money (WTA) on side of the farmers, as well as appreciation of standards in animal welfare enabled by money (WTP). We presume that the dairy processing industry as a mediator can do the job under prescribed construction (as follows).

The final approach for this section is a conversion of (18). If we move lactation years and milk yields to the left side (in equations $18 \mathrm{a}$ and $\mathrm{b}$ ) declaring them endogenous, the farmer's concern matches with consumers'. It is a linearized version of the above structural relationship for getting practice. (Actually, one could work out a percentage change that would be more appropriate in indexing). However, in the second (18b on quality) scoring of milk as an index is retrieved from consumer inquiry. Combining them and solving for $\mathrm{g}$ and $\mathrm{y}$ : 


$$
\begin{aligned}
& \omega_{a, 1} l_{a}+\omega_{a, 3} y_{a}=\omega_{a, 4} e_{a}-\omega_{a, 2} g_{a} \\
& \omega_{a, 1} l_{a}+\omega_{c, 1} y_{a}=i_{a}-\omega_{c, 1} g_{a}
\end{aligned}
$$

We get 1 and $y$ as endogenous and g, e and i are seemingly exogenous. I.e. when (if) they are fixed in parallel the payment scheme can respond by setting the corresponding bonus (premium) along an achieved qualification of grazing and effort, given the index. Instead of lactation years and milk yields for farmers this is sufficient. It enables the dairy company to generalize on WTP and get service. It can be retrieved from consumers. For example, applying a contingent valuation to consumers' assessments (above as index) it includes different WTP levels for animal friendly practices. So far it was assumed that a simple price gap (mark-up) exists with different attributes and labelling amid milk marketed. By now, apparently, the processing company has choices and tries to get as much revenue out of higher indexed/priced milk, i.e. it can change brands. If the price (WTP) which can be attained is a function of achievable scoring, this opens an extra dimension for optimization. The index is set (optimized) by the industry which can claim autonomy over treating a standard which suits its interest most.

Finally, there is the job of addressing farmers individually or groups of farmers in terms of efforts and knowledge on what the practices and labour requirements are/consist of/include. In case of a detailed analysis of the dairy industry on farmer participation and subtle incentive constraint, deliberations are needed. There is scope to correctly meet the effort-response-to-bonus payment. But for making things simple, it can be claimed that efforts are linearly dependent on response. For practical reason the dairy processing company can eventually generically regress efforts on labour returns and then identify the farms with which it negotiates on an individual scale.

$$
e_{a}=\omega_{m, 0}+\omega_{m, 1} z_{a}+\omega_{m, 2} x_{a}
$$

At least, what is needed is an anticipated willingness to put effort into the provision of animal friendliness (as a service) by bonus $z_{a}$. However, the bonus can be proportional to the milk price $\left(1+z_{a}\right)$ (below). The bonus itself is flexible and, since the government only vaguely prescribes "milk from grass", participating farmers have a double, though interlinked choice: they decide on their effort (by individual optimization of efforts given the bonus), and the negotiation gives individual solutions (achieved with the dairy processing company). For reference the procedures are similar to those of Zusman (1976, respectively Rausser et al., 2011).

\subsection{Defining Standards in Objective Functions for Bargaining}

To sum up and proceed, campaigns must be established, etc. For that, there is a need for a minimum of mark-up requirement (communicable with consumers) which is based on the linkage between, for example, images like milk from grazing and quality. This works as well with product images (like hay-milk-cheese) and is explicitly related to brand creation. Branding serves as a bargaining position because we need references for cooperation. It is a matter of specifying the index (dairy as dependent on quality initiative for milk from healthy cows).

$$
\begin{aligned}
& \pi_{d}=\left[1-\alpha_{1}\right] \alpha_{t} p_{w}^{e}\left[\xi_{11}^{*} k_{c}+\xi_{12}^{*} k_{a}+\xi_{13}^{*} v_{t}\right]+\alpha_{1}\left[p_{c}^{e}\left[[1-\theta] i_{g, a}-\theta i_{g, c}\right]-c_{m}^{m}\right]\left[\xi_{21}^{*} k_{c}+\xi_{22}^{*} k_{a}+\xi_{23}^{*} v_{t}\right] \\
& \left.\left[p_{a}^{e}\left[1+i_{a}^{s}\right]-c_{a}^{m}\right]-z_{a}^{l}\right]\left[\xi_{14}^{*} g_{a}+\xi_{13}^{*} i_{a}+\xi_{15}^{*} e_{a}\right] k_{a}-z_{g}^{g} g_{a} k_{a}-\left[\omega_{a 43}-.5 \omega_{a 43} y_{c} k_{c}+y_{a} k_{a}\right]\left[y_{c} k_{c}+y_{a} k_{a}\right]
\end{aligned}
$$

Finally, the objective function (20) implicitly captures the initially given three possible criteria for bargaining (higher life expectancy, lower milk yield and grazing) which are animal welfare indicators. (Note the suggested game is not about social welfare. Yes WTP increase well-being of consumers, but it is only indirectly covered.) Then looking for internal knowledge on response for efforts (above in the synthesis), we can reduce bargaining to one variable left: grassing for bonus. Grazing includes hay making, pasture, etc. and refers to cows foraging "naturally". It is actually a farm's own forage system (sources being "natural"). There is flexibility in agreements and grazing reflects the overall alternatives to forage. To make the intention clear in modelling: we reduce the number of variables for bargaining to grazing; followed by a bonus for service originated in WTP; but have life-expectancy in mind. Also, because health is indirectly stipulated through grazing, (as aspirations (number of lactations and yields would be indirect indicators, but difficult to monitor)) the dairy processing company starts to rethink its procurement and business policy. To do so, we can advance the problem by choices on market share allocation and grazing supports on the one side, and procurement and promotion, price transmission, etc. and bonus on the other side.

Please note that this is an academic contribution, not a real bargain. However, to reflect on real bargaining (compared to anonymous markets where only prices determine supply), a dairy firm (in the presented logic) can 
control (restrict) LVF delivery and develop a preference for AVF. At the general level the dairy serves sectors and cows. It is up to the management to decide where preferences for cow types lie, i.e. where business opportunities appear to be most prosperous. Our analysis is stepwise and offers the inclusion of negotiation.

A further remark: For policy, in a first step, we can exemplify the composition of milk deliveries according to an optimization with given references to existing price transmission and apparently introduction of a bonus system. From optimization the total number of cows (in a reference scenario) appears and the dairy can start to think of referenced bargains built on its power. Having a stake in pre-size and mode of business, i.e. if no specific bargains have prevailed so far, there is still scope for entering into bargaining as an advantage in order to impose modified conditions. About the structure of bilateral negotiations, which have to be referenced (because power comes from alternatives: Zusman, 1989), an expansion in the number of cows for animal friendly farming AVF has an implication for the number of cows in the conventional LVF sector. Hereby we follow the proposition that a dairy factor works at its capacity and looks for opportunities to make a profit in conventional and animal friendly farming. Structurally a gain from an animal friendly market comes at the cost of losing in the conventional market. The conventional sub-sector faces a danger of losing processing capacities, unless it offers a better bargain in form of a discount (lower transmission) on price. Modelling this interaction vice versa has a counter effect on increasing the number of cows (decreasing) in AVF. For example if requests of bonuses are too high there is a tendency not to contract The dairy industry can negotiate along its structure of milk sources to find alternatives for specifying contracts. The important thing is: bargains become interactive and referenced. In the case of a dairy processing company which bargains with individual farms on grazing and supply, these are contractual details. The size is equivalently defined by the overall business and in competition with milk from the source: AVF or LVF. As will be shown below, power comes from referenced institutions to be principal or agent.

\section{Structure of Bargaining}

So far the individual objective functions have been presented under the auspices of creating interest in cooperation for animal welfare by active promotion of a dairy industry, willingness of farmers and consumers. Perhaps as an economist, because he thinks animal welfare cannot be marketed, and as an animal welfare expert, because he thinks markets are not resourceful, it might not work spontaneously (market failure); but it has scope for bargaining (below). Since we claimed that anyone can improve welfare (interest) by cooperation, it shall end in reciprocal rewarding and finding contractual parameters. Willingness is fuelled by money from consumers and industry takes the lead. We must speak about influence of the dairy industry on getting more AVFs on behalf of consumers' WTP and we suggest how this aim can be reached. In order to make a profit from milk and cows produced by hay and grass, sales must increase, higher prices must be transmitted on the basis of contracts and contracts must be embedded.

However, as follow-up, an institutional economist can provide the needed analysis (factual or about what will be the likely outcome) based on bargaining parameters. These parameters determine the exchange. The outcome depends on specific options which industry and sub-sectors face, respectively. Although this does not explain the theory of bargaining in detail (Rausser et al. 2011), let us reconcile: the basics refer to inclusion of power and an optimization of parameters which coincide with the optimal decision of any participants. Parameters are contingent on offers, found interactively and are reciprocate. Power is measured as reference, and we get a weight for interests of participants in the game (simulation). A simple version for a depiction of bargaining and handling this power is composed of two additional elements: firstly, to calculate references and then insert these into the overall objective function, and finally to have a reference for a switching of the milk source from providers. Note that for an overall profit the dairy firm seeks image improvement by procuring milk from animal friendly farms.

In Figure 2, power coefficients are the diameter on the derivation of an overarching (weighted) objective function, which combines interests and can serve as explanation. For explanation: power is the slope of a unified (summed) interest function built along achievements in interest. Cooperation either means that, in a principal agent mode of finding exchange and incentive parameters, one partner is the principal and the other is the agent, or vice versa. For that proceeding, two corner solutions are obtained. Moreover, corners are stratified and a linear combination gives the slope, intersections and degree (90 degrees equal power). Gains in negotiation, beyond corner solutions, are optimized with new preference functions (weights: slope $\psi$ ). A unified solution is obtained. The procedure serves to establish a set of references and parameters explaining bargains beyond having an individual interest for calculation. 


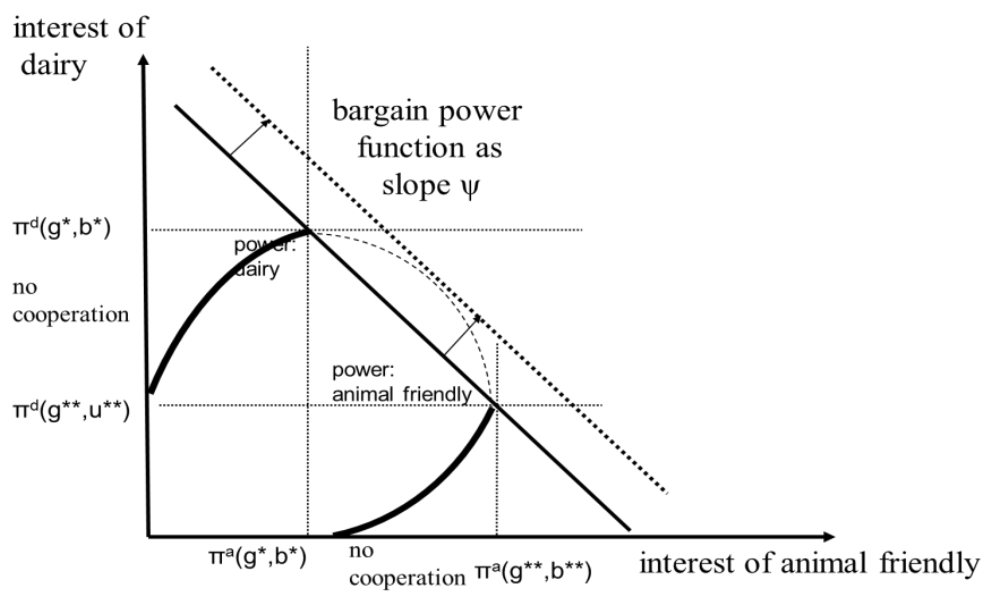

Figure 2. Depiction of a Bargaining Concept

In Figure 2, power coefficients are the diameter on the derivation of an overarching (weighted) objective function, which combines interests and can serve as explanation. For explanation: power is the slope of a unified (summed) interest function built along achievements in interest. Cooperation either means that, in a principal agent mode of finding exchange and incentive parameters, one partner is the principal and the other is the agent, or vice versa. For that proceeding, again two corner solutions are obtained. Moreover, corners are stratified and a linear combination gives the slope, intersections and degree (90 degrees equal power). Gains in negotiation, beyond corner solutions, are optimized with new preference functions (weights: slope $\psi$ ). A unified solution is obtained. The procedure serves to establish a set of references and parameters explaining bargains beyond having an individual interest for calculation.

To clarify further: interest (referenced) of AVFs is an alignment of "economic" aims and "animal welfare" concern. As discussed above the underlying optimization of AVFs refers to a strategy (to target life expectancy) which suits the development of qualified herds. Herds can be a referenced target. (Like, for instance, in the case of a consumer who minimizes income to fulfil utility; as target, an AVF can minimize effort or losses to get his herd of most healthy cows.) Perceiving the AVF as a farmer who sets a target of animal friendliness himself and seeks to minimize economic losses, this enables us to bring targets into play (negotiation). The farmer will judge whether the dairy industry, by paying him, gives him support for pursuing this interest (healthy cows). Recursively it opens the question for reference: i.e. targeting (positions) should not be undermined. For society, facts (life expectancy) can be set. In fact, an AVF sets the reference target which can be achieved in case of, perhaps, indirect promotion. When modelling this, direct marketing (promotion) as an option (cost element) can be included; own processing/marketing is a reference. Such an approach enables the industry to target life expectancy in a political economy mode and it surpasses pure economy tactics.

Applying this background for a conceptual framework to sponsoring both, farmer-dairy negotiation and bilateral (also triangle) negotiation with the industry on the one side and the farms on the other side, the achieved negotiation with competitors serves as mutual reference. The difficulty is that references and power values are endogenous because the dairy firm has power to choose between different types of farms. This creates a special power situation (Zusman, 1989). Indeed, because of endogeneity of power and mutual references raised by the alternative to obtain gains from cooperation with diverse farmer types, not a single equation is maximized. The game is embodied in a set of equations, which gives the bargaining.

$$
W=\sum_{i} \psi_{a, i} I_{a, i}\left(g_{a, i}, \pi_{a, i}\right)+\sum_{j} \psi_{c, i} \boldsymbol{I}_{c, j}\left(\boldsymbol{k}_{c, j}, \boldsymbol{\alpha}_{c, j}\right)+\boldsymbol{I}_{d}\left(\boldsymbol{g}_{c, i}, \boldsymbol{k}_{c, j}, z_{a, i}, \boldsymbol{\alpha}_{c, j}\right)
$$

and the weights are endogenous.

$$
\psi_{a}=\frac{\boldsymbol{I}_{a}^{k}\left(\boldsymbol{l}_{a}, \boldsymbol{Z}_{a}\right)-\boldsymbol{t}_{a, r}}{\boldsymbol{I}_{d}^{k}\left(\boldsymbol{l}_{a}, \boldsymbol{g}_{c}, \boldsymbol{\alpha}_{c}, \boldsymbol{p}_{c}\right)-\boldsymbol{t}_{d, c, r}}
$$




$$
\boldsymbol{\psi}_{c}=\frac{\boldsymbol{I}_{a}^{k}\left(\boldsymbol{g}_{c}, \boldsymbol{p}_{c}\right)-\boldsymbol{t}_{c, r}}{\boldsymbol{I}_{d}^{k}\left(\boldsymbol{l}_{\boldsymbol{a}}, \boldsymbol{g}_{c}, \boldsymbol{z}_{c}, \boldsymbol{p}_{c}\right)-\boldsymbol{t}_{d, a, r}}
$$

Equations (22) represent power of individual farm types and the sum of the dairy gaining form mutual contracts with w number of farms. Bargaining is a cooperative game and the gains from cooperation must exceed the reference which is given in the set of equations (23):

$$
\begin{gathered}
\boldsymbol{I}_{a}^{k}\left(\boldsymbol{l}_{a}, z_{a}\right)-\boldsymbol{t}_{a, r} \geq 0 \\
\boldsymbol{I}_{a}^{k}\left(\boldsymbol{g}_{c}, \boldsymbol{p}_{c}\right)-\boldsymbol{t}_{c, r} \geq 0 \\
\boldsymbol{I}_{d}^{k}\left(\boldsymbol{l}_{a}, \boldsymbol{g}_{c}, \boldsymbol{\alpha}_{c}, \boldsymbol{p}_{c}\right)-\boldsymbol{t}_{d, a, r} \geq 0 \\
\boldsymbol{I}_{d}^{k}\left(\boldsymbol{l}_{\boldsymbol{a}}, \boldsymbol{g}_{c}, \boldsymbol{\alpha}_{c}, \boldsymbol{p}_{c}\right)-\boldsymbol{t}_{d, c, r} \geq 0
\end{gathered}
$$

For the calculation of the references we have to distinguish between the scope of the dairy company and the farms in the different sectors. For the dairy industry which can choose a reference in terms of knowing the alternatives in AVF or LVF, it is the bi-lateral opportunity from which it can gain. For the farms, their opportunity lies in not contracting under conditions proposed by the dairy company. In fact, for LFV it would be opportune to produce milk for the world market and receive a price declared by dairy industry. Perhaps the same applies to local dairy processing companies. For the AVF, the reference is a continuation without being rewarded. This also applies to AVF which are in the process of strategic choice. Yet there is a problem of specification. In an elaborated version including structural change, strategic verges must address farmers who are facing the problem of either becoming (or staying) AVF or following the LVF strategy. Strategies are associated with the superior aim of farmers to stay in business. We may envisage farming without specifically addressing life expectancy. In this case an optimization of life expectancy is a residual (impact) of optimization.

\section{Summary}

This contribution deals with options to establish a bargaining between dairy industry and animal friendly milk producers in order to promote animal health. It is suggested to perceive life expectancy as a core indicator for health and the article argues in favour of it being an interface. This indicator is linked to grazing and practices requesting efforts. Increased efforts in farms which pursue a strategy of animal health are to be financed by the consumers' willingness to pay. We work out how to extend a niche of animal friendly milk production. We start by making a reference to different strategies: maximizing long-term land value through the highest stocking of high yielding cows on the one side and maximizing qualified herds with longevity of cows on the other side. Strategies are explained and we refer to leveraging as underlying strategic decisions of actors. In any case, objective functions, interests and a game theoretical outline are presented to obtain a full picture of the possibility to model bargaining based on internal power. As a result, we arrive at a conceptual framework concerning finding solutions for improved business in a dairy sector which respects animal health. Cooperation, threats and world markets are included as a reference to make things realistic.

\section{References}

Alvarez, A., del Corral, J., Solís, D., \& Pérez, J. A. (2008). Does Intensification Improve the Economic Efficiency of Dairy Farms?. Journal of Dairy Science, 91(9), 3693-3698. https://doi.org/10.3168/jds.2008-1123

Arla (2017). Arlafoods company web page. Retrieved December, 11, 2017. Retrieved from https://www.arlafoods.de/produkte/arlabio/?gclid=EAIaIQobChMI19XqlYu52QIVp7ztCh3y7AtJEAAYASA AEgJF4vD_BwE

BMEL (2015). Bundesministerium für Ernährung und Landwirtschaft. Wege zu einer gesellschaftlich akzeptierten Nutztierhaltung. Gutachten. Wissenschaftlicher Beirat Agrarpolitik. Berlin. Retrieved January, 27, 2018. Retrieved from http://www.bmel.de/SharedDocs/Downloads/Ministerium/Beiraete/Agrarpolitik/GutachtenNutztierhaltung.p df?_blob=publicationFile (last access on 27.01.2018). 
Choisis, J. P., Sourdril, A., Deconchat, M., Balent, G., \& Gibon, A. (2010). Understanding regional dynamics of mixed crop-livestock agricultural systems to support rural development in South-western France uplands. Cahiers Agricultures, 19(2), 97-103.

Dauderstädt, P. (2013). Success Factors in Strategic Corporate Venturing (Doctoral Dissertation, University Bonn, Germany). Retrieved from https://www.depositonce.tu-berlin.de/bitstream/11303/3841/1/Dokument_12.pdf

Dobson, H., Smith, R. F., Royal, M. D., Knight, C. H., \& Sheldon, I. M. (2007). The High-producing Dairy Cow and its Reproductive Performance. Reproduction in Domestic Animals, 42(s2), 17-23. https://doi.org/10.1111/j.1439-0531.2007.00906.x

Dyball, R., \& Newell, B. (2015). Understanding Human Ecology: a systems approach to sustainability, Chapter 10 Consumers and global food systems, 178-195, Routledge, Abington.

Elzen, B., Geels, F. W., Leeuwis, C., \& Van Mierlo, B. (2011). Normative contestation in transitions 'in the ma-king': Animal welfare concerns and system innovation in pig husbandry. Research Policy, 40(2), 263-275. https://doi.org/10.1016/j.respol.2010.09.018

EU (2016) Commission regulation 2016/304. Retrieved from http://eur-lex.europa.eu/legal-content/EN/TXT/?uri=CELEX\%3A32016R0304

Firth, R., \& Yamey, B. S. (2004). Capital, Saving and Credit in Peasant Society. Studies from Asia, Oceania, The Caribbean and Middle America. Routledge. London.

Fitzgerald, D. (2003). Every Farm a Factory: The Industrial Ideal in American Agriculture. Yale University Press, New Haven.

Ford, S. A., \& Shonkwiler, J. S. (1994). The effect of managerial ability on farm financial success. Agricultural and Resource Economics Review, 23(2), 150-157. https://doi.org/10.1017/S1068280500002264

Franklin, A. (1999). Animals and modern cultures: sociology of Human-Animal Relationship in Modernity. Sage, London.

Harvey, D., \& Hubbard, C. (2013). Reconsidering the political economy of farm animal welfare: An anatomy of market failure. Food Policy, 38,105-114.

Kaeserebellen (2018). Kaeserebellen company web page. Retrieved from http://www.kaeserebellen.com/hay-milk/

Ingvartsen, K. L., Dewhurst, R. J., \& Friggens, N. C. (2003). On the relationship between lactation performance and health: is it yield or metabolic imbalance that cause production diseases in dairy cattle? A position paper. Livestock Science, 83(2), 277-308. https://doi.org/10.1016/S0301-6226(03)00110-6

Jongeneel, R., \& Ge, L. (2005). Explaining growth in Dutch agriculture: prices, public R\&D, and technological change. Paper prepared for presentation at the 11th International Congress of the EAAE, The Future of Rural Europe in the Global Agri-Food System. Copenhagen, Denmark. Retrieved from http://library.wur.nl/WebQuery/wurpubs/344720

Kielland, C., Skjerve, E., Østerås, O., \& Zanella, A. J. (2010). Dairy farmer attitudes and empathy toward animals are associated with animal welfare indicators. Journal of Dairy Science, 93(7), 2998-3006. https://doi.org/10.3168/jds.2009-2899

Langford, F. M., \& Sott, A. W. (2012). Culled early or culled late: economic decisions and risks for welfare in dairy cows. Animal Welfare, 21(1), 41-45. https://doi.org/10.7120/096272812X13345905673647

Müller-Lindenlauf, M., Deittert, C., \& Köpke, U. (2010). Assessment of environmental effects, animal welfare and milk quality among organic dairy farms. Livestock Science, 128(1), 140-148. https://doi.org/10.1016/j.livsci.2009.11.013

March, J. G. (1978). Bounded Rationality, Ambiguity, and the Engineering of Choice. The Bell Journal of Economics, 9(2), 587-608. https://doi.org/10.2307/3003600

Mench, J. A. (2008). Farm animal welfare in the U.S.A.: Farming practices, research, education, regulation, and assurance programs. Applied Animal Behaviour Science, 113(4), 298-312. https://doi.org/10.1016/j.applanim.2008.01.009

Mench, J. A. (2017). Advances in Agricultural Animal Welfare: Science and Practice. Cambridge.

Nocella, G., Hubbard, L., \& Scarpa, R. (2010). Farm Animal Welfare, Consumer Willingness to Pay, and Trust: Results of a Cross-National Survey. Applied Economic Perspectives and Policy, 32(2), 275-297. 
https://doi.org/10.1093/aepp/ppp009

Ohl, F., \& van der Staay, F. J. (2012). Animal welfare: At the interface between science and society. The Veterinary Journal, 192(1), 13-19. https://doi.org/10.1016/j.tvj1.2011.05.019

O'Kelly, M., \& Bryan, D. (1996). Agricultural Location theory: von Thunen's contribution to economic geography. Progress in Human Geography, 20(4), 457-475.

Oltenacu, P. A., \& Algers, B. (2005). Selection for Increased Production and the Welfare of Dairy Cows: Are New Breeding Goals Needed?. A Journal of the Human Environment, 34(4), 311-315. https://doi.org/10.1579/0044-7447-34.4.311

Pryce, J. E., Royal, M. D., Garnsworthy, P. C., \& Mao, I. L. (2004). Fertility in the high-producing dairy cow. Livestock Production Science, 86(1), 125-135. https://doi.org/10.1016/S0301-6226(03)00145-3

Rausser, G. C., Swinnen, J., \& Suzman, P. (2011). Political power and economic policy. Theory, Analysis and empirical Application. Cambridge University Press.

Rauw, W. M., Kanis, E., Noordhuizen-Stassen, E. N., \& Grommer, F. J. (1998). Undesirable side effects of selection for high production efficiency in farm animals: a review. Livestock Production Science, 56(1), 15-33. https://doi.org/10.1016/S0301-6226(98)00147-X

Robinson, D. T., Brown, D. G., Parker, D. C., Schreinemachers, P., Janssen, M. A., Huigen, M., ... Barnaud, C. (2007). Comparison of empirical methods for building agent-based models in land use science. Journal of Land Use Science, 2(1), 31-55. https://doi.org/10.1080/17474230701201349

Rodriguez-Martinez, H., Hultgren, J., Båge, R., Bergqvist, A.-S., Svensson, C., Bergsten, ... Gustafsson, H. (2008). Reproductive Performance in High-producing Dairy Cows: Can We Sustain it Under Current Practice?. IVIS Reviews in Veterinary Medicine, 1(108), 1-23.

Sen, A. (1973). Behaviour and the Concept of Preference. Economica, 40(159), 241-259. https://doi.org/10.2307/2552796

Sunding, D., \& Zilberman, D. (2001). Chapter 4 The agricultural innovation process: Research and technology adoption in a changing agricultural sector. Handbook of Agricultural Economics, 1, 207-261. https://doi.org/10.1016/S1574-0072(01)10007-1

Thompson, P. B. (2004). Getting Pragmatic about Animal Welfare. In: McKenna, E. and Light, A. Animal Prag-matism: Rethinking Human no-Human relationships. Indiana University Press, Bloomington, 140-150.

Vranken, L., \& Swinnen, J. (2006). Land Rental Markets in Transition: Theory and Evidence from Hungary. World Development, 34(3), 481-500. https://doi.org/10.1016/j.worlddev.2005.07.017

Wagner, P. (2007). Zur Wirtschaftlichkeit der Milchviehhaltung: Einflussfaktoren und regionale Unterschiede. In: Nutztierhaltung: Herausforderungen und Implikationen für die Forschung. Agrarspectrum, 49, 7-90.

Walsh, S. W., Williams, E. J., \& Evans, A. C.,O. (2011). A review of the causes of poor fertility in high milk producing dairy cows. Animal Reproduction Science, 123(3-4), 127-138. https://doi.org/10.1016/j.anireprosci.2010.12.001

Weinrich, R., Kühl, S., Zühlsdorf, A., \& Spiller, A. (2014). Consumer Attitudes in Germany towards Different Dairy Housing Systems and Their Implications for the Marketing of Pasture Raised Milk. International Food and Agribusiness Management Review, 17(4), 205-222.

Weiss, C. R. (1997). Do they come back again? The symmetry and reversibility of off-farm employment. European Review of Agricultural Economics, 24(1), 65-84. https://doi.org/10.1093/erae/24.1.65

Wisten, J. R., Kerchner, C. D., Richardson, A., Lichau, A., \& Hyman, J. M. (2010). Trends in the Northeast dairy industry: Large-scale modern confinement feeding and management-intensive grazing. Journal of Dairy Science, 93(4), 1759-1769. https://doi.org/10.3168/jds.2008-1831

Xueqin, Z., Demeter, R. M., \& Lansink, A. O. (2012). Technical efficiency and productivity differentials of dairy farms in three EU countries: the role of CAP subsidies. Agricultural Economics Review, Thessaloniki, 13(1), 66-92.

Yeats, J. W. (2010). Death is a welfare issue. Journal of Agricultural and Environmental Ethics, 23(3), 229-241.

Zimmermann, A., Heckelei, T., \& Pérez, Domínguez, I. (2009). Modelling farm structural change for integrated ex-ante assessment: review of methods and determinants. Environ. Science \& Policy, 12(5), 601-618. 
https://doi.org/10.1016/j.envsci.2009.01.014

Zimmermann, A., \& Heckelei, T. (2012). Structural change of European dairy farms - a cross-regional analysis.

Journal of Agricultural Economics, 63(3), 576-603. https://doi.org/10.1111/j.1477-9552.2012.00355.X

Zhu, X., Demeter, R. M., \& Oude, Lansink, A. (2012). Technical efficiency and productivity differentials of dairy farms in three EU countries: the role of CAP subsidies. Agricultural Economics Review, 13(1), 66-92.

Zusman, P. (1976). The incorporation and measurement of social power in economic models. International Economic Review, 17(2), 447-62. https://doi.org/10.2307/2525712

Zusman, P. (1989). Peasants' Risk Aversion and the Choice of Marketing Intermediaries and Contracts: A Bargaining Theory of Equilibrium Market Contracts. In: Bardahn, P., The Economic Theory of Agrarian Institutions. Oxford, 1989, 316.

\section{Copyrights}

Copyright for this article is retained by the author(s), with first publication rights granted to the journal.

This is an open-access article distributed under the terms and conditions of the Creative Commons Attribution license (http://creativecommons.org/licenses/by/4.0/). 